PATRICIA DE SÁ E BENEVIDES RODRIGUES ALVES

\title{
EFEITOS DA MOXIDECTINA NO COMPORTAMENTO SEXUAL DE RATOS MACHOS
}

Dissertação apresentada ao Instituto de Psicologia da Universidade de São Paulo como parte dos requisitos para obtenção do grau de Mestre em Neurociências e Comportamento.

Orientadora: Prof ${ }^{\mathrm{a}}$. Dra. Helenice de Souza

Spinosa

São Paulo

2003 
Ficha Catalográfica preparada pelo Serviço de Biblioteca e Documentação do Instituto de Psicologia da USP

Rodrigues-Alves, P. S. B.

Efeitos da moxidectina no comportamento sexual de ratos machos. / Patricia de Sá e Benevides Rodrigues-Alves. - São Paulo: s.n., 2003. $55 \mathrm{p}$.

Dissertação (mestrado) - Instituto de Psicologia da Universidade de São Paulo. Núcleo de Pesquisa em Neurociências e Comportamento.

Orientadora: Helenice de Souza Spinosa.

1. Análise do comportamento 2. Comportamento sexual (animal)

3. Coordenação motora 4. Moxidectina 5. GABA 6. Ratos

I. Título. 


\section{EFEITOS DA MOXIDECTINA NO COMPORTAMENTO SEXUAL DE RATOS MACHOS}

\section{PATRICIA DE SÁ E BENEVIDES RODRIGUES ALVES}

\section{BANCA EXAMINADORA}

(Nome e Assinatura)

(Nome e Assinatura)

(Nome e Assinatura)

Dissertação defendida e aprovada em: 
"Aprender é a única coisa de que a mente nunca se cansa, nunca tem medo nem se arrepende"

Leonardo Da Vinci

(Artista renacentista italiano, séc.

XVI) 
À minha filha Dora, meu amor, obrigada pelo incentivo e ajuda.

Aos meus pais, Adélia e Marcello, por me ensinarem a gostar de estudar.

Ao meu marido, José Eduardo, pelo apoio. 
HOMENAGEM

À Maria Helena Rodrigues Alves, obrigada pela valiosa ajuda na realização deste sonho. 


\section{AGRADECIMENTOS}

À Professora Helenice de Souza Spinosa, pela dedicação, carinho e orientação segura no desenvolvimento deste trabalho. E à sua filha, Renata, escusas pelas horas roubadas de seu convívio.

À Professora Maria Martha Bernardi, pelas palavras de incentivo, sua amizade e valiosa ajuda em todas as horas.

Ao Professor Luciano Freitas Felício, pela preciosa colaboração durante os experimentos e exame de qualificação.

À Professora Célia Aparecida Paulino, pelas ótimas sugestões apresentadas por ocasião do exame de qualificação.

À Professora Maria Helena Leite Hunziker, pela amizade, incentivo e idéias muito úteis.

Ao Professor Jorge Camilo Flório, pelo auxílio nas estatísticas, e principalmente por sua amizade.

A todos os Professores que tive o prazer de conhecer, reencontrar e conviver durante a realização deste mestrado, pela simpatia, apoio e colaboração.

À Cláudia, Idalina, Rosires, Ademir, Luiz e Nélson, funcionários do Biotério do Departamento de Patologia da Faculdade de Medicina Veterinária e Zootecnia da Universidade de São Paulo, pela amizade e grande colaboração na realização dos experimentos.

À Cássia Medea, pela colaboração na realização dos desenhos desta dissertação.

À Flávia, minha irmã, pelo incentivo e carinho na troca de conhecimentos, na compilação dos dados e na editoração do trabalho no computador.

Aos meus irmãos Manoel, Marcello, Renata e família pelo incentivo e apoio.

À Adriana, Aline, Ana Paula, Benito, Cláudia, Cristina, Daniela, Dario, Elizabeth, Marcela, Maria Rita, Priscila, Ricardos, Rosana, Simone, pela amizade e ajuda na realização dos experimentos.

Aos demais colegas da pós-graduação dos cursos de Neurociências e Comportamento e de Patologia Experimental e Comparada, pelo privilégio de sua amizade e convívio.

Às Secretárias Idalina, Silvia, Cristina, Marguiti e Cláudia, pela amizade e colaboração. 
Aos Funcionários da Secretaria de pós-graduação do Instituto de Psicologia, pela atenção e apoio.

À D. Lúcia, Rosa, Mara, Ana, Cláudia e demais funcionários das Bibliotecas do Instituto de Psicologia e da Faculdade de Medicina Veterinária e Zootecnia da Universidade de São Paulo, pelo atendimento carinhoso e auxílio na compilação das referências.

E, finalmente, a todos que, direta ou indiretamente, colaboraram na realização deste mestrado, o meu muito obrigada. 
Os experimentos desta dissertação foram realizados no Departamento de Patologia da Faculdade de Medicina Veterinária e Zootecnia da Universidade de São Paulo 


\section{SUMÁRIO}

1 INTRODUÇÃO

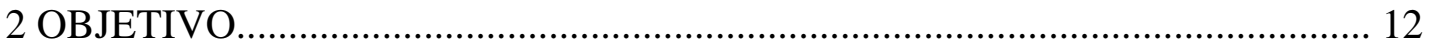

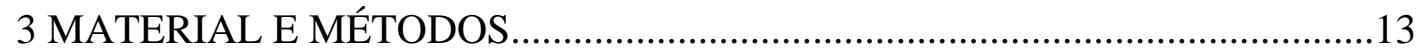

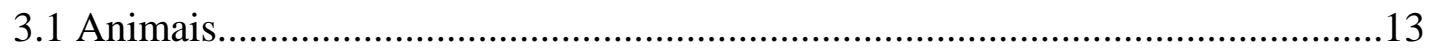

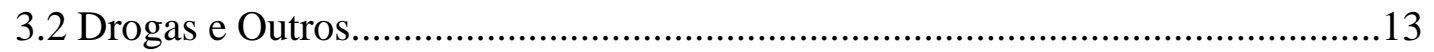

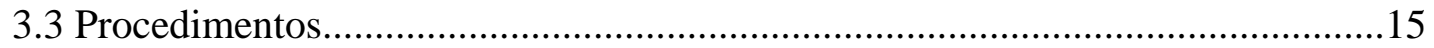

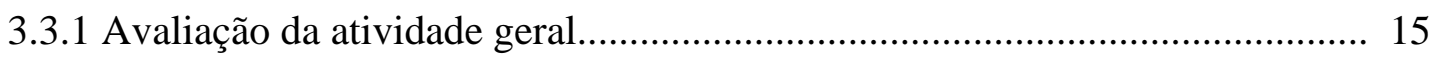

3.3.2 Avaliação da coordenação motora..............................................................16

3.3.3 Avaliação do comportamento sexual..........................................................18

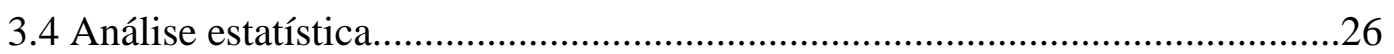

4 DELINEAMENTO EXPERIMENTAL E RESULTADOS..................................27

4.1 Experimento 1 Efeitos da moxidectina na atividade geral de ratos observados no campo aberto.

4.2 Experimento 2 Efeitos da moxidectina na coordenação motora de ratos

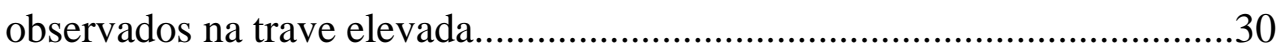

4.3 Experimento 3 Efeitos da moxidectina no comportamento sexual de ratos machos inexperientes. 
4.4 Experimento 4 Efeitos da moxidectina no comportamento sexual de ratos machos

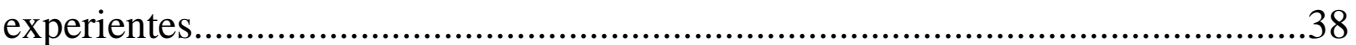

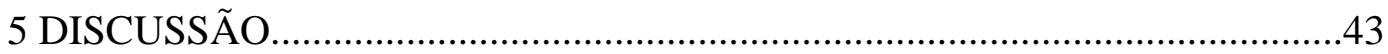

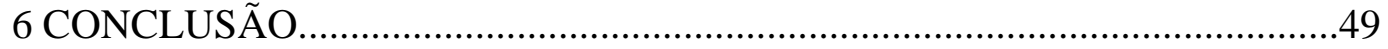

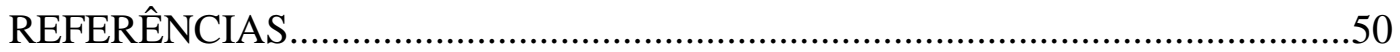




\section{LISTA DE FIGURAS}

\section{Figura n.}

\section{Página}

1 Desenho esquemático da trave

elevada..............................

2 Desenho esquemático da caixa para observação do comportamento

sexual..........................................................

3 Estágios do comportamento sexual de ratos machos conduzindo $\mathrm{a}$ uma intromissão

4 Estágios do comportamento sexual de ratos machos conduzindo ejaculação

5 Efeitos da moxidectina na atividade geral de ratos observados no aberto. campo

6 Efeitos da moxidectina na coordenação motora de ratos avaliados na trave elevada.

7 Efeitos da moxidectina nas latências de parâmetros do comportamento sexual de ratos inexperientes

8 Efeitos da moxidectina na freqüência de alguns parâmetros do comportamento sexual de ratos inexperientes.

9 Efeitos da moxidectina em índices do comportamento sexual de ratos inexperientes

10 Efeitos da moxidectina nas latências de parâmetros do comportamento sexual de ratos experientes. 
11 Efeitos da moxidectina na freqüência de alguns parâmetros do comportamento sexual de ratos experientes.

12 Efeitos da moxidectina em índices do comportamento sexual de ratos experientes. 


\section{LISTA DE TABELAS}

\section{Tabela n.}

\section{Página}

1 Escores atribuídos ao comportamento do rato observado na região que corresponde a $1 \mathrm{~m}$ no centro da trave........

2 Efeitos da moxidectina na atividade geral de ratos observados no

campo aberto.

3 Efeitos da moxidectina na coordenação motora de ratos avaliados na trave elevada.................................................

4 Efeitos da moxidectina em parâmetros do comportamento sexual de ratos inexperientes observados 24 ou 72 horas após a administração da droga

5 Efeitos da moxidectina em parâmetros do comportamento sexual de ratos experientes observados 24 ou 72 horas após a administração da droga 


\section{RESUMO}

RODRIGUES-ALVES, P.S.B. Efeitos da moxidectina no comportamento sexual de ratos machos. São Paulo, 2003. 55p. Dissertação (Mestrado). Núcleo de Pesquisa em Neurociências e Comportamento, Instituto de Psicologia, Universidade de São Paulo.

A moxidectina é uma droga antiparasitária, do grupo das milbemicinas, utilizada em animais domésticos. Em mamíferos seu mecanismo de ação envolve o GABA, neurotansmissor que tem um papel relevante na regulação do comportamento sexual. Assim, o presente trabalho estudou os efeitos da moxidectina no comportamento sexual de ratos machos. Uma vez que alterações na função motora podem interferir na manifestação deste comportamento, avaliou-se, inicialmente, a atividade geral no campo aberto e a coordenação motora na trave elevada, e posteriormente, o comportamento sexual de ratos inexperientes e experientes. A avaliação da atividade geral dos ratos observados no campo aberto mostrou que, mesmo em altas doses (2,0 e $20,0 \mathrm{mg} / \mathrm{kg}$ ), a moxidectina não altera o comportamento de ratos no campo aberto. Esta droga, porém, prejudicou a coordenação motora dos animais avaliados na trave elevada, sendo este efeito atribuído, ao menos em parte, à ação da moxidectina em receptores GABAérgicos. Os resultados obtidos na avaliação do comportamento sexual de ratos inexperientes mostraram redução da motivação sexual dos animais que receberam $0,2 \mathrm{mg} / \mathrm{kg}$ de moxidectina e foram observados 24 ou 72 horas depois. Nenhuma alteração significante foi observada nos diferentes parâmetros do comportamento sexual dos ratos experientes, indicando que a experiência sexual pode reverter os efeitos desta droga. Estes resultados mostraram que a moxidectina prejudicou o comportamento sexual de ratos machos inexperientes e a coordenação motora, efeitos estes atribuídos a uma ação central desta droga em receptores $\mathrm{GABA}_{\mathrm{A}}$. 


\begin{abstract}
RODRIGUES-ALVES, P. S. B. Effects of moxidectin on male rats' sexual behavior.

São Paulo, 2003. 55p. Master Thesis. Núcleo de Pesquisa em Neurociências e Comportamento, Instituto de Psicologia, Universidade de São Paulo.
\end{abstract}

The moxidectin is an antiparasitic drug that is used in domestic animals. It is a semi-synthetic milbemycin. Its mechanism of action, in mammals, involves GABA, neurotransmiter that has an important role in the regulation of the sexual behavior. Thus, the present work studied the effects of the moxidectin in male rats sexual behavior. Due to the fact that alterations in the motor function can interfere in the expression of this behavior, it was evaluated, initially, the general activity in the open field and the motor coordination at wooden dowel, and later, the sexual behavior of naïve and experienced rats. The evaluation of the general activity of the rat observed in the open field showed that, even in high doses (2.0 and 20.0 $\mathrm{mg} / \mathrm{kg}$ ), the moxidectin do not alter the behavior of the rats in open field. However, this drug was able to impair the motor coordination of the animals at the wooden dowel. As a matter of fact, this effect is due, at least part of it, to the action of the moxidectin in GABAergics receptors. The results achieved in the evaluation of naïve male rats' sexual behavior showed reduction of the sexual motivation of the animals that received $0.2 \mathrm{mg} / \mathrm{kg}$ of moxidectin and were observed after 24 or 72 hours later. No significant alteration was detected in the various parameters of the experienced rats' sexual behavior, indicating that the sexual experience could revert the effects of this drug. The moxidectin impair the sexual behavior of naive male rats and the motor coordination, and the reasons that caused these effects were attributed to a central action of the moxidectin at $\mathrm{GABA}_{\mathrm{A}}$ receptors. 


\section{INTRODUÇÃO}

Na década de 1970 foram descobertos dois grupos de substâncias químicas, que inovaram o tratamento das doenças parasitárias que acometem os animais domésticos: as milbemicinas e as avermectinas.

Inicialmente, foram descobertas as milbemicinas, em 1973, por pesquisadores da Sankyo, que mostraram efeito acaricida e inseticida (SHOOP et al., 1995); a denominação milbemicina reflete este efeito: milbe = ácaro e myc = fungo. Mais tarde, em 1975, pesquisadores da Merck descobriram as avermectinas ( $a=$ sem, verm $=$ vermes e ect $=$ ectoparasitos), que mostraram atividade contra ácaros, insetos e nematódeos (CAMPBELL, 1989; STEEL, 1993; SHOOP et al., 1995). A moxidectina foi desenvolvida por American Cyanamid e foi lançada na América do Sul em 1989, e em 1991 na África do Sul e Nova Zelândia (STEEL, 1993)

Ambos grupos farmacológicos são derivados macrocíclicos da lactona, obtidos a partir do processo de fermentação de fungos de solo, actinomicetos, do gênero Streptomyces (BURG et al., 1979; TAKIGUCHI et al., 1980; SHOOP et al, 1995; AYRES e ALMEIDA, 2002); a principal diferença entre os grupos é que as milbemicinas não possuem um grupo dissacarídeo na posição 13 do anel lactônico (CAMPBELL, 1989; STEEL, 1993; SHOOP et al., 1995; AYRES e ALMEIDA, 2002). Estes agentes abriram novas perspectivas de estudo na área dos antiparasitários derivados de microrganismos, sendo chamados de endectocidas, isto é, agentes que combatem endo- e ectoparasitos.

O primeiro agente a ser comercializado foi a ivermectina, em 1981, sendo recomendada como endectocida para animais de produção; posteriormente, 
apareceram a abamectina, a doramectina e, mais recentemente, a eprinomectina e a selamectina (AYRES e ALMEIDA, 2002).

As milbemicinas são obtidas da fermentação do Streptomyces hygroscopicus e do S. cyaneogriseus (MISHIMA et al, 1983; SHOOP et al., 1995; AYRES e ALMEIDA, 2002). O fungo produz vários compostos homólogos denominados de A e B, conforme apresentem grupos hidroxi- ou metoxi- na posição 5. Dentre as milbemicinas que são comercializadas para uso em animais e na agricultura tem-se: milbemicina $\mathrm{D}$, milbemicina $\mathrm{A}_{3} / \mathrm{A}_{4}$, milbemicina $\mathrm{A}_{3} / \mathrm{A}_{4}$-oxima e moxidectina. Esta última é um derivado semi-sintético produzido pelo Streptomyces cyanogriseus sub-espécie noncyanogenus.(AYRES e ALMEIDA, 2002); foi desenvolvida pela Cyanamid, sendo lançada na América do Sul em 1989 (STEEL, 1993). A moxidectina é comercializada para bovinos e ovinos, em solução aquosa a 1\%, para administração por via subcutânea, e a 0,1\% usada para ovinos, por via oral, na dose de $200 \mu \mathrm{g} / \mathrm{kg}$ (STEEL, 1993). No Brasil é comercializada para uso em Medicina Veterinária, com os nomes de Cydectin NF (frasco ampola com moxidectina a $1 \%$ para uso em bovinos), Equest (frasco amplola com moxidectina a 2\% para uso em eqüinos) e Biodectin (moxidectina a 0,5\% associada a vacina contra linfadenite caseosa, enterotoxemia, carbúnculo sintomático, edema maligno, hepatite necrótica e tétano, indicada para ovinos) (MANUAL DE PRODUTOS VETERINÁRIOS, 2002). A moxidectina é também, em outros países, indicada para uso em caprinos e animais de companhia.

Tanto as avermectinas como as milbemicinas são compostos lipofílicos, praticamente insolúveis em água, porém solúveis em vários solventes orgânicos como o clorofórmio, acetona, dimetil sulfóxido, ciclo-hexano e dimetilformamina (AYRES e ALMEIDA, 2002). A alta lipossolubilidade permite que estas substâncias 
atravessem com maior facilidade as barreiras celulares e facilita sua deposição no tecido adiposo.

A moxidectina pode ser absorvida quando administrada por vias oral e subcutânea. Em ovinos, cerca de 20 \% da dose de moxidectina administrada por via oral é absorvida e, como é bastante lipossolúvel, é encontrada em alta concentração no tecido adiposo e em concentrações muito mais baixas em outros tecidos (FAO/WHO, 1995).

CRAVEN et al (2001) compararam a farmacocinética da moxidectina e da ivermectina após administração intravenosa em suínos magros e gordos. Neste estudo observou-se que a moxidectina tem maior volume aparente de distribuição e meia-vida de eliminação mais longa do que a ivermectina, enquanto que a velocidade de depuração foi menor, levando a detecção de moxidectina, no plasma, por mais de 40 dias. A distribuição e eliminação da moxidectina, nos animais magros, foram mais rápidas do que nos animais gordos, indicando sua maior afinidade pelo tecido adiposo.

A moxidectina é muito pouco biotransformada no organismo animal. DUPUY et al (2001) observaram, in vitro, o metabolismo da moxidectina marcada em microssomas hepáticos de bovino, ovino, caprino, veado, rato, suíno e coelho. A maior taxa de metabolização foi obtida nos microssomas de ovinos $(32,7 \%)$ e a menor em suínos $(0,8 \%)$.

A moxidectina é excretada principalmente pelas fezes de forma íntegra e em menor proporção na urina (2\%) e no leite (AYRES e ALMEIDA, 2002), sendo por isto desaconselhado seu uso em fêmeas lactantes. Nos Estados Unidos da América não é permitida sua utilização, em bovinos leiteiros, devido a possível presença de resíduos no leite. CARCELES et al. (2001) observaram em cabras 
tratadas com a dose terapêutica de moxidectina $(0,2 \mathrm{mg} / \mathrm{kg})$, por vias subcutânea e oral, a presença de resíduos no leite por até 40 dias após a administração de dose única da droga.

GOKBULUT et al. (2001), trabalhando com cavalos, detectaram a presença de moxidectina nas fezes por 8 dias após a administração da droga. PEREZ et al. (2001) confirmaram estes achados, mostrando que 90\% da droga é eliminada nos primeiros 8 dias, e que continua a ser detectada nas fezes por até 75 dias após sua administração por via oral.

ALVINERIE et al (2000) observaram, em cavalos, que o jejum prévio à administração da moxidectina, por via oral, induz modificações no seu comportamento farmacocinético. Assim, considerando-se que o jejum pode diminuir o fluxo biliar e a excreção fecal, e que estas são as principais vias de eliminação da droga, a moxidectina permanecerá por tempo maior no organismo do animal, fazendo com que o jejum prévio ao tratamento seja útil para melhorar o controle dos parasitos de cavalos.

O pico de concentração plasmática da moxidectina após a administração subcutânea, em bovinos, é de 7-8 horas; quando administrada por via oral a ovinos e ratos, o pico é de 10 horas (FAO/WHO, 1995). A meia-vida plasmática da moxidectina é cerca de 80 horas em bovinos e ovinos (FAO/WHO, 1995), enquanto que no fígado é de 9-12 dias e no tecido adiposo é de 12-15 dias, em bovinos (AYRES e ALMEIDA, 2002).

Em estudos de toxicidade aguda, a moxidectina mostrou-se moderadamente tóxica quando administrada, por via oral, a ratos e camundongos, mostrando uma dose letal 50\% (DL50) de 50-100 mg/kg (FAO/WHO, 1995). 
EMAN e ABDALLA (2000) mostraram, em coelhos que tanto a ivermectina como a moxidectina, administradas em doses terapêuticas $(0,2 \mathrm{mg} / \mathrm{kg})$, promovem efeitos adversos na fertilidade. Foi observada diminuição da concentração de células espermáticas, da porcentagem de motilidade progressiva e de espermatozóides vivos e dos níveis séricos de testosterona; e aumento da porcentagem do total de anomalias espermáticas. Alem disto, observou-se diminuição da proteína total sérica e aumentam do nível sérico das transaminases uréia e creatinina

Os efeitos adversos são observados quando a moxidectina é administrada aos animais em doses muito altas; sinais de neurotoxicidade são caracterizados por depressão, ataxia, tremores, inquietação, dificuldade de visão, coma e morte (AYRES e ALMEIDA, 2002). Os cães das raças Collie, Shetland Sheepdog, Old England Sheepdog e Australian Sheepdog são mais sensíveis aos efeitos tóxicos das avermectinas e milbemicinas, podendo manifestar sinais de intoxicação como depressão e ataxia; são menos comuns midríase, êmese, sialorréia, tremores, letargia e coma, levando a morte; convulsões são raras (PAUL et al, 2000; AYRES e ALMEIDA, 2002). Gatos também podem apresentar distúrbios neurológicos. O mecanismo da toxicidade em algumas raças de cães e gatos é desconhecido, mas parece estar relacionado com a permeabilidade da barreira hematoencefálica à estas drogas.

Em um estudo de toxicidade em camundongos que receberam a moxidectina, por 28 dias na alimentação, os animais mostraram tremores e hipersensibilidade ao toque; e aqueles que receberam a maior dose, $32 \mathrm{mg} / \mathrm{kg} / \mathrm{dia}$, vieram a óbito (FAO/WHO, 1995). Em ratos que receberam a droga também por 28 dias da mesma maneira, observou-se na dose de 31mg/kg/dia, ataxia, tremores, 
salivação, pilo-ereção e diurese; na dose de 23 mg/kg/dia ou mais atrofia difusa, dose-dependente, em vários órgãos como fígado, rins, coração, baço, adrenais, testículos, epidídimos e ovários. O grupo de ratos que recebeu a dose de 12 $\mathrm{mg} / \mathrm{kg} /$ dia ou mais, apresentou hipersensibilidade ao toque nos dias 2 e 3 após o início do tratamento. Resultados similares foram observados em outro experimento, no qual a moxidectina foi administrada na alimentação por 13 semanas (FAO/WHO, 1995).

Na avaliação de toxicidade reprodutiva em uma única geração, a moxidectina foi administrada, a ratos, por 9 semanas em doses de até $10 \mathrm{mg} / \mathrm{kg} / \mathrm{dia}$, antes do período de acasalamento e durante a gestação e lactação. Neste estudo, nenhuma ninhada do grupo que recebeu a maior dose sobreviveu e a taxa de sobrevivência decresceu na progênie de animais que receberam as doses menores, porém não houve nenhum achado que pudesse ser atribuído a efeitos na fertilidade (FAO/WHO, 1995). No estudo de três gerações, no qual os ratos receberam doses de moxidectina de até $0,83 \mathrm{mg} / \mathrm{kg} / \mathrm{dia}$, por 70 dias antes do período de acasalamento, não houve efeitos na mortalidade ou na fertilidade, exceto na dose maior empregada, sendo observada uma leve redução no peso dos machos e redução significante na sobrevivência dos filhotes (FAO/WHO, 1995).

No estudo de teratogenicidade, em ratos, a moxidectina foi administrada nas doses de 10 e $12 \mathrm{mg} / \mathrm{kg} / \mathrm{dia}$, sendo observadas evidências de toxicidade materna e fetal, caracterizada por aumento na incidência de fenda palatina e costelas flutuantes ou com ossificação incompleta, porém não houve evidência de efeitos teratogênicos (FAO/WHO).

Embora a atividade antiparasitária tanto das avermectinas como das milbemicinas tenha sido descrita a mais de duas décadas, seu mecanismo de ação 
ainda não foi totalmente elucidado. As dificuldades em identificar os mecanismos pelos quais estas drogas exercem seus efeitos devem-se ao fato de que são estudadas em sistemas biológicos distintos e por diferentes metodologias.

Os estudos sobre o mecanismo de ação das avermectinas são mais abundantes do que aqueles das milbemicinas e como ambas tem atividades antiparasitárias semelhantes, acredita-se que os mecanismos de ação também sejam similares (FISHE E MROZIK, 1992; ARENA et al, 1995; FORRESTER et al., 2002). No mesmo sentido, os trabalhos sobre o mecanismo de resistência desenvolvido pelos parasitos a estas drogas também auxiliam no entendimento do seu mecanismo de ação (CONDER et al., 1993; SHOOP et al 1995; MOLENTO et al, 1999; KOHLER, 2001).

Há vários trabalhos mostrando que a ivermectina atua de maneira semelhante ao neurotransmissor glutamato, como agonista de um canal inibitório, o canal de cloro $\left(\mathrm{Cl}^{-}\right)$, controlado pelo glutamato (ARENA, 1994; CLELAND, 1996; CULLY et al, 1996; WOLSTENHOLME, 1996); estes canais são encontrados apenas em invertebrados (crustáceos, insetos e nematódeos).

Estas endectocidas também se ligam com alta afinidade aos canais de $\mathrm{Cl}^{-}$ controlados pelo ácido gama-aminobutírico (GABA) (DUCE e SCOT, 1985; DAWSON et al, 2000). Nos insetos e artrópodes estas drogas interferem na transmissão dos impulsos nervosos entre células nervosas e musculares, pois é nesta junção neuromuscular que estão os receptores GABAérgicos. Interagem também com receptores GABA no cérebro de vertebrados (mamíferos), mas sua afinidade pelos receptores de invertebrados é aproximadamente 100 vezes maior (RHOER e ARENA, 1995; SCHAEFFER e HAINES, 1989; TRACY e WEBSTER, 1996). 
A distribuição do GABA no Sistema Nervoso Central (SNC) de mamíferos é irregular e sua atuação como neurotransmissor inibitório tem sido bastante estudada em diferentes regiões cerebrais, como, por exemplo, no sistema nigro-estriatal e na área pré-óptica medial (KANDEL et al., 1995). Esta última é a principal região envolvida na mediação do comportamento sexual de mamíferos machos, uma vez que lesões nesta área levam a perda da atividade sexual (HART e LEEDY, 1985; MAS, 1995).

BITRAN e HULL (1987) fizeram uma retrospectiva sobre as bases farmacológicas do comportamento sexual de ratos machos, mostrando a participação de vários neurotransmissores e, em particular, do GABA. Assim, é relatado que durante o período refratário pós-ejaculação, a concentração de GABA no fluído cérebro-espinhal aumenta drasticamente (FALASCHI et al., 1981), mostrando o papel inibitório do GABA na atividade copulatória. No mesmo sentido, AGMO e PAREDES (1985), fazendo a administração sistêmica de várias drogas GABAérgicas em ratos, mostraram diminuição na porcentagem e número de montas e intromissões após a administração do agonista de receptores GABA A $_{\text {, THIP (4,5,6,7-tetra- }}$ hidroisoxazol[5,4-C] piridina-3-ol), enquanto o agonista de receptores $\mathrm{GABA}_{\mathrm{B}}$, baclofen promoveu inibição quase completa do comportamento sexual. Por outro lado, a administração sistêmica de bicuculina, um antagonista destes receptores, não interferiu em nenhum parâmetro da cópula. E mais, a administração concomitante de bicuculina e THIP produziu efeito inibitório intenso no comportamento sexual.

Uma possível explicação para este último achado, no qual um antagonista potencializa a ação de um agonista, foi feita por BITRAN e HULL (1987), que levaram em consideração o fato de que os receptores GABAérgicos são heterogêneos. Há pelo menos dois tipos de receptores: $\mathrm{GABA}_{A}$ e $\mathrm{GABA}_{\mathrm{B}}$. Os 
receptores $\mathrm{GABA}_{\mathrm{A}}$ são ativados pelo THIP e muscimol, e bloqueados pela bicuculina e picrotoxina. Os receptores $\mathrm{GABA}_{B}$ são ativados pelo baclofen, que é um potente agonista destes, com pequena ou nenhuma atividade nos sítios de ligação de GABA . Assim, o efeito da bicuculina potencializando a inibição do comportamento sexual produzida pelo THIP, pode ser atribuído ao bloqueio pré- e pós-sináptico de receptores $\mathrm{GABA}_{\mathrm{A}}$. O bloqueio pré-sináptico resulta em liberação endógena do neurotransmissor GABA, a qual ativa, preferencialmente, sítios $\mathrm{GABA}_{\mathrm{B}}$, uma vez que os sítios $\mathrm{GABA}_{\mathrm{A}}$ estão bloqueados pela bicuculina. Esta hipótese sugere que o THIP pode ter algum efeito em receptor $\mathrm{GABA}_{\mathrm{B}}$ (além de sua ação agonista em receptores $\mathrm{GABA}_{\mathrm{A}}$ ) e que a inibição do comportamento sexual de machos pelo GABA é mediada pela ativação de receptores $\mathrm{GABA}_{\mathrm{B}}$.

Por outro lado, alguns experimentos têm mostrado que o bloqueio estéreoespecífico de sítios de ligação dos receptores $\mathrm{GABA}_{\mathrm{A}}$ da área pré-óptica medial promove um potente efeito estimulante do comportamento copulatório (FERNANDEZ-GUASTI et al., 1985, 1986c). A administração de bicuculina diretamente na área pré-óptica medial resultou tanto na redução drástica do intervalo pós-ejaculatório, como na eliminação virtual da vocalização ultra-sônica normalmente emitida durante este período refratário (FERNANDEZ-GUASTI et al., 1986c), enquanto a administração intracranial de bicuculina acelerou o início do comportamento sexual de ratos ingênuos, que foram castrados e tratados com testosterona (FERNANDEZ-GUASTI et al., 1986a). Já a administração do agonista muscimol, na área pré-óptica medial de ratos experientes, que não foram castrados, resultou na supressão do comportamento sexual, expresso pela diminuição na proporção de animais que realizaram montas, intromissões e ejaculação (FERNANDEZ-GUASTI et al., 1986b). Assim, o bloqueio dos supostos sítios dos 
receptores $\mathrm{GABA}_{\mathrm{A}}$ da área pré-óptica medial facilitou tanto o início do comportamento copulatório após a ejaculação, bem como o restabelecimento do comportamento copulatório em animais castrados que receberam testosterona.

A influência do GABA no reflexo de ereção peniana também tem sido investigado. LEIPHEIMER e SACHS (1988) observaram que a administração sistêmica de diferentes doses (1 e 2 mg/kg) de baclofen promoveu diminuição, dosedependente, da proporção de ratos exibindo ereções no teste do reflexo peniano em posição supina.; porém, estas mesmas doses não tem efeito no comportamento de cópula. Por outro lado, a administração sistêmica de THIP ou bicuculina não afeta o reflexo peniano nem o comportamento de cópula. Estes dados mostram a maior influência dos receptores $\mathrm{GABA}_{\mathrm{B}}$ no reflexo de ereção peniana. No mesmo sentido, MEISEL e SACHS (1994), descrevendo o comportamento sexual de machos em diferentes espécies animais, referem que a estimulação de receptores $G_{A B A}$ inibe os reflexos de ereção, enquanto que os receptores $\mathrm{GABA}_{\mathrm{A}}$ não têm influência na ereção.

Os receptores $\mathrm{GABA}_{\mathrm{B}}$ estão presentes no corno dorsal da medula espinhal lombo-sacra (BOWERY et al, 1984; DAVIDOFF e HACKMAN, 1985) e a influência destes nas respostas do reflexo de ereção peniana tem sido estudadas. BITRAN e HULL (1987) relataram que a administração de 0,2 $\mu$ g de baclofen, por via intratecal, visando atuação na medula espinhal lombo-sacra, causou aumento da latência para ereção e redução no número de ereções; doses maiores (0,4 e 0,8 $\mu$ g) diminuíram o número de animais exibindo ereção peniana. A maior dose produziu também um leve efeito inibitório no comportamento copulatório, caracterizado por aumento na latência para ejaculação em conseqüência de um maior número de montas sem intromissão. Por outro lado, quando da administração de baclofen, por 
via intratecal, porém, visando atuação na medula espinhal torácica, não se observaram efeitos nas respostas penianas (BITRAN et al., 1989).

Do exposto acima, nota-se que a grande maioria dos estudos realizados sobre o mecanismo de ação das lactonas macrocíclicas, em mamíferos, envolve o neurotransmissor GABA, e que este neurotransmissor tem um papel relevante na regulação do comportamento sexual. Assim, o presente trabalho estudou os efeitos da moxidectina no comportamento sexual de ratos machos. 


\section{OBJETIVO}

Estudar os efeitos da moxidectina no comportamento sexual de ratos machos.

Para tanto, avaliou-se atividade geral no campo aberto, a coordenação motora na trave elevada e o comportamento sexual de ratos ingênuos e experientes. 


\title{
3. MATERIAL E MÉTODOS
}

\subsection{Animais}

Foram utilizados ratos Wistar adultos, provenientes do biotério do Departamento de Patologia da Faculdade de Medicina Veterinária e Zootecnia da Universidade de São Paulo. Os animais foram alojados em caixas de polipropileno com tampa metálica medindo 40 × 50 × $20 \mathrm{~cm}$, em número de cinco por caixa, por um período não inferior a uma semana antes de serem colocados nas diferentes situações experimentais. Estas caixas foram mantidas em sala com temperatura controlada $\left(22 \pm 2^{\circ} \mathrm{C}\right)$ e ciclo de 12 horas claro/escuro; a luz foi acesa às 7:00 horas, exceto no experimento de avaliação do comportamento sexual quando empregou-se um ciclo de luz parcialmente invertido, sendo a luz ligada às 22:00 horas.

Cada animal foi utilizado em apenas um experimento.

\subsection{Drogas e outros}

\author{
Moxidectina (Cydectin ${ }^{\circledR}$ - Fort Dodge Saúde Animal Ltda., Campinas) \\ Óleo de amêndoas (Leclerc Industrial Ltda., São Paulo) \\ Xilazina 1\% (Rompum ${ }^{\circledR}$ - Bayer) \\ Cloridrato de Quetamina - 100 mg/ml (Vetaset ${ }^{\circledR}$ - Fort Dodge) \\ Povidine ${ }^{\circledR}$ tópico (Drogasil) usado para assepsia da pele das ratas
} submetidas à ovariectomia 
Vetaglós ${ }^{\circledR}$ pomada (Univet S.A. Indústria Veterinária): usada no tratamento das feridas cirúrgicas das ratas submetidas à ovariectomia

Benzoato de 17ß-estradiol (Sigma)

Progesterona (Sigma)

Leite Condensado Mocinha ${ }^{\circledR}$ (Nestlé Brasil Ltda) usado no teste da coordenação motora como reforço positivo.

Etanol (Cooperalcool ${ }^{\circledR}$ - Coopersucar Indústria Brasileira): usado para limpeza dos aparelhos e caixas utilizados nos experimentos, numa solução a 5 \%.

A moxidectina foi diluída em óleo de amêndoas, obtendo-se as concentrações de 0,2; 2,0 e 20,0 mg/ml Os animais receberam $1 \mathrm{ml} / \mathrm{kg}$ de uma destas preparações, por via subcutânea (SC).

A xilazina e a quetamina foram administradas, por via intraperitoneal (IP), para a anestesia das ratas submetidas a ovariectomia bilateral.

O 17ß-estradiol e a progesterona foram diluídos em óleo de amêndoas, na concentração $50 \mu \mathrm{g} / \mathrm{ml}$ e $2 \mathrm{mg} / \mathrm{ml}$, respectivamente, e administrados, por via SC, nas fêmeas ovariectomizadas utilizadas na avaliação do comportamento sexual, em volume de 0,1 ml/kg, 54 e 6 horas, respectivamente, antes do início de cada sessão experimental.

\subsection{Procedimentos}

\subsubsection{Avaliação da Atividade Geral}

A atividade geral de ratos foi avaliada através de observação direta destes animais em um campo aberto, construído baseado naquele descrito por BROADHURST (1960). Este aparelho é constituído de uma arena circular de 
madeira com 97 cm de diâmetro e parede metálica com 28 cm de altura, pintadas de branco. O assoalho da arena é dividido em 25 regiões com áreas aproximadamente iguais, delimitadas por duas circunferências concêntricas de raios diferentes e segmentos de retas radiais demarcados em preto em sua superfície. A arena está distante $80 \mathrm{~cm}$ do solo, apoiada em pés metálicos. A $72 \mathrm{~cm}$ acima do assoalho da arena, existe um teto apoiado em estruturas metálicas, no qual fixam-se três lâmpadas incandescentes de 40 watts cada uma; fixada também ao redor do teto, há uma cortina de tule branca, que permite total observação do animal dentro da arena.

Cada animal foi colocado individualmente no centro da arena e observado por um período de 3 minutos em cada sessão, na qual se avaliaram os seguintes parâmetros:

- freqüência de locomoção: uma unidade de locomoção corresponde ao ato do animal penetrar com as quatro patas em uma das divisões do chão da arena;

- freqüência de levantar: uma unidade de levantar corresponde à postura do animal permanecer apoiado nas patas posteriores, com o tronco perpendicular ao chão, tendo a cabeça dirigida para cima, podendo tocar ou não com as patas anteriores as paredes do campo aberto;

- duração de imobilidade: tempo, em segundos, no qual o animal permanece imóvel, podendo ou não mexer as vibrissas.

- defecação: número de bolos fecais eliminado pelo animal ao término da sessão

O registro dos dois primeiros parâmetros foi feito com o auxílio de um contador elétrico (Kacil, modelo CCS-01) e a duração de imobilidade foi feita empregando-se cronógrafo manual (Technos, modelo 802). 
Os animais dos grupos controle e experimentais foram observados intercaladamente. Antes e depois da introdução de cada animal no campo aberto, este foi limpo com uma solução de etanol a 5\%, a fim de homogeneizar a situação experimental, eliminando possíveis odores deixados pelo animal anterior na arena.

\subsubsection{Avaliação da coordenação motora}

A coordenação motora foi avaliada na trave elevada, adaptando-se o modelo descrito por JEFFERY e BLAKEMORE (1997). Este aparelho consiste de uma trave de madeira com $18 \mathrm{~mm}$ de largura e espessura por $2 \mathrm{~m}$ de comprimento, com uma plataforma de $10 \mathrm{~cm}^{2}$ por $18 \mathrm{~mm}$ de espessura, em cada uma das extremidades. Esta trave fica apoiada em pés com $20 \mathrm{~cm}$ de altura, sendo estes posicionados nas plataformas e no centro da trave. As plataformas e a trave são pintadas de branco, sendo que a trave possui duas marcas verticais pretas delimitando o comprimento de 1 m na porção central desta. Durante o experimento esta trave fica apoiada sobre o balcão na sala de observação.

Para avaliação da coordenação motora, inicialmente o rato é treinado a andar sobre a trave. Sucintamente, no primeiro dia, coloca-se uma pequena porção de leite condensado (reforço positivo) sobre ambas plataformas e, a seguir, introduz-se o rato para acostumar-se ao ambiente e ao reforço. Em dias subseqüentes o animal é colocado sobre a trave, próximo da plataforma com o reforço, e com a cabeça voltada para esta. A seguir, o rato é colocado sobre a trave, porém cada vez mais distante da plataforma com reforço, até que este tenha condição de atravessar a trave por inteiro, atingindo a plataforma oposta. O rato deve retornar a plataforma inicial, sempre recebendo o reforço no final de cada travessia. Isto é feito individualmente, 
em sessões diárias de 5 min cada. Dá-se por encerrado o período de treinamento, com duração de 7 a 10 dias, quando o rato consegue ir e voltar, sem parar, por duas vezes (4 travessias). Os animais que não conseguem andar na trave em 10 dias são eliminados do experimento.

O desempenho do rato na trave é avaliado através de uma escala de escores (Tabela 1). Para tanto, quando o animal caminha na porção central da trave (1 m entre as marcas verticais), atribui-se um escore para cada passo dado com o membro pélvico voltado para o observador. Ao término de cada sessão, soma-se os escores obtidos por cada animal nas 4 travessias.

Antes e após a colocação de cada animal no aparelho, este foi limpo com um pano umedecido em água, e após cada sessão com solução de etanol a 5\%.

Tabela 1. Escores atribuídos ao comportamento do rato observado na região que corresponde a $1 \mathrm{~m}$ no centro da trave, conforme adaptada do modelo proposto por JEFFERY e BLAKEMORE (1997).

\begin{tabular}{cl}
\hline escore & Posição do membro pélvico \\
\hline 0 & Normal \\
1 & Posicionado no limite da espessura da trave \\
2 & Posicionado abaixo do limite da trave
\end{tabular}

\subsubsection{Avaliação do comportamento sexual.}

Os animais antes de serem submetidos à avaliação do comportamento sexual foram mantidos, ao menos por um mês, em uma sala com ciclo de luz parcialmente invertido (luz acesa às 22:00 h), sendo este comportamento avaliado sempre na fase escura do ciclo, entre 14:00 e 18:00 h. Este período é suficiente para a adaptação dos 
animais a um novo regime de iluminação (RAMIREZ et al, 1979). A observação deste comportamento também teve lugar nesta sala, que, durante o experimento, foi iluminada com duas lâmpadas infravermelhas de 20 Watts cada.

O comportamento sexual foi avaliado baseado no método descrito por AHLENIUS, LARSSON (1984). Para tanto foi utilizada uma caixa de madeira medindo 56 × 35 x $31 \mathrm{~cm}$, pintada de cinza, com tampa móvel e a parede frontal de vidro; o piso foi coberto com uma camada de $\pm 3 \mathrm{~cm}$ de maravalha de madeira que servia de cama aos animais (caixa de observação).

Para avaliação do comportamento sexual dos machos utilizou-se fêmeas sexualmente receptivas (iscas), que foram submetidas a uma cirurgia para retirada dos ovários e receberam injeções de hormônios. Sucintamente, as ratas foram anestesiadas com 0,1 mL/kg de uma solução de quetamina e xilazina (1:2) administradas por via intraperitoneal. Após a constatação da anestesia, procedeu-se a tricotomia e a assepsia da pele (com álcool e povidine tópico), sendo foi feita uma incisão no flanco direito para exposição do ovário; fez-se, então, uma ligadura no ligamento meso-ovariano com fio Corrente ${ }^{\circledR}$ de algodão preto $\mathrm{n}^{\circ} 24$ e retirou-se a gônada com auxílio de um bisturi. A seguir, procedeu-se a sutura do peritônio, tecido subcutâneo e pele com pontos contínuos. Repetiu-se o mesmo procedimento para a retirada do ovário esquerdo, e ambas feridas cirúrgicas foram tratadas com vetaglós ${ }^{\circledR}$ pomada.. Estas fêmeas foram utilizadas como iscas após 21 dias, no mínimo, tempo este necessário para a eliminação dos hormônios circulantes (AGMO et al, 1987).

A receptividade sexual das ratas foi induzida pela administração de $50 \mu \mathrm{g} / \mathrm{kg}$ de 17- $\beta$-estradiol e 2,0 mg/kg de progesterona, 54 e 6 horas, respectivamente, antes do início da observação do comportamento sexual. Cerca de 20 min antes desta observação, a receptividade foi testada colocando-se a fêmea com um macho 
sexualmente ativo, na caixa de observação, permitindo-se a realização de algumas montas e observando-se a presença de lordose nas ratas, ou seja, a presença simultânea de flexão côncava do dorso, desvio lateral da cauda e extensão do pescoço (SÖDERSTEN, 1979; SÖDERSTEN e ENEROTH, 1980; SÖDERSTEN et al, 1986) Estas ratas iscas somente eram reutilizadas após um intervalo mínimo de duas semanas.

Para a avaliação do comportamento sexual, cada macho foi retirado de sua gaiola moradia e colocado individualmente na caixa de observação. Então, aguardouse 5 min e foi introduzida a fêmea isca nesta caixa, dando inicio a observação do comportamento sexual do macho, por 40 minutos. Os seguintes parâmetros foram avaliados:

- Latência para primeira monta (LPM): tempo decorrido desde a introdução da fêmea na caixa de observação até a primeira monta com ou sem intromissão vaginal.

- Latência para primeira intromissão (LPI): tempo decorrido desde a introdução da fêmea na caixa de observação até a primeira monta com intromissão vaginal. A intromissão foi inferida pela observação do padrão motor característico, isto é, monta com movimento profundo da pélvis (thrusting) e desmonta rápida, acompanhado de lordose da fêmea, e após a desmonta observa-se limpeza genital do macho e este não monta em seguida.

- $\quad$ Número de montas incompletas (MI): definidas como aquelas montas sem intromissão do pênis na vagina da fêmea, até a primeira ejaculação.

- Número de intromissões (NI): montas com intromissão vaginal até a primeira ejaculação, incluindo a intromissão ejaculatória. 
- Latência para ejaculação (LPE): tempo decorrido desde a introdução da fêmea na caixa de observação até a ejaculação menos a LPI, ou seja, é o intervalo entre a primeira intromissão e a primeira ejaculação. Considerase ejaculação uma monta com duração superior a dois segundos, lordose da fêmea, levantar e balouçar do tronco pelo macho, seguida de ausência de interesse sexual nos minutos seguintes (período refratário - duração normal entre 4 a $8 \mathrm{~min})$.

- Latência para primeira monta pós-ejaculação (LPMP): tempo decorrido desde a primeira ejaculação até a primeira monta.

- Latência para primeira intromissão pós-ejaculação (LPIP): tempo decorrido desde a primeira ejaculação até a primeira intromissão (latência pós-ejaculatória ou período refratário).

- Número de montas incompletas pós-ejaculação (MIP): idêntico a MI desde a primeira ejaculação até o final do tempo de observação.

- Número de intromissões pós-ejaculação (NIP): idêntico a NI desde a primeira ejaculação até o final do tempo de observação, incluindo as intromissões ejaculatórias.

- Número total de ejaculações (NE): Número de ejaculações realizadas pelo animal no tempo total de observação.

As latências foram registradas com o auxílio de cronógrafos manuais (Technos) e expressas em minutos.

Foram calculados, com estes parâmetros, somente para os animais que ejacularam pelo menos uma vez durante o período de observação (40 min) os seguintes índices: 
- Número total de montas até a primeira ejaculação (TM): obtido somandose MI com NI.

- Número total de montas no tempo total de observação (TMT): é a soma total das montas incompletas e das intromissões em todo o tempo de observação dos animais, isto é, TMT = MI + NI + MIP + NIP.

- Freqüência de montas por minuto: é a razão entre a TM e o tempo transcorrido entre a primeira monta e a primeira ejaculação.

- Freqüência de intromissões por minuto: é a razão entre NI e LPE.

- Intervalo inter-intromissões: é a latência para a primeira ejaculação (LE) dividido pelo número de intromissões até a primeira ejaculação (NI).

- Eficiência copulatória (EC em \%): é o número de intromissões divido pelo número total de montas até a primeira ejaculação vezes 100 , isto é, $\mathrm{EC}=(\mathrm{NI} / \mathrm{TM}) \times 100$.

- Índice de atividade sexual (IAS): este, conforme proposto por AGMO et al (1987), calcula-se, para todos os animais do experimento, da seguinte forma:

$\operatorname{IAS}=\{[\log (1 / \operatorname{LPM}) \times \mathrm{t}]+[\log (1 / \mathrm{LPI}) \times \mathrm{t}]+[\log (1 / \mathrm{LE}) \times \mathrm{t}]+\sqrt{\mathrm{TM}}+\mathrm{e}\}$

Onde:

$$
\begin{aligned}
& \text { LPM = Latência para primeira monta } \\
& \text { LPI = Latềncia para primeira intromissão } \\
& \text { LPE = Latência para primeira ejaculação } \\
& \sqrt{ } \text { TM40 = Raiz quadrada do número total de montas incompletas e } \\
& \text { intromissões no tempo total de observação (40 min) } \\
& \mathrm{t}=\text { Tempo total de observação } \\
& \text { e = “0” se o animal não ejacular e " } 4 \text { ” se o animal ejacular }
\end{aligned}
$$




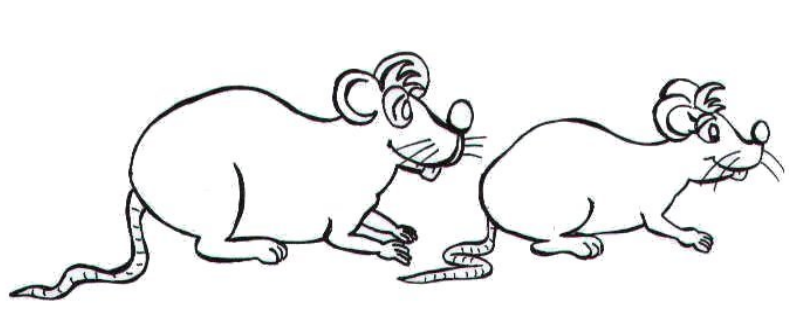

A

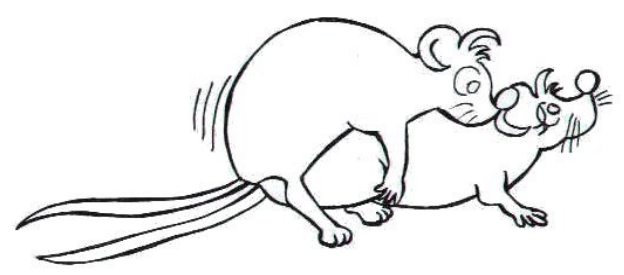

C

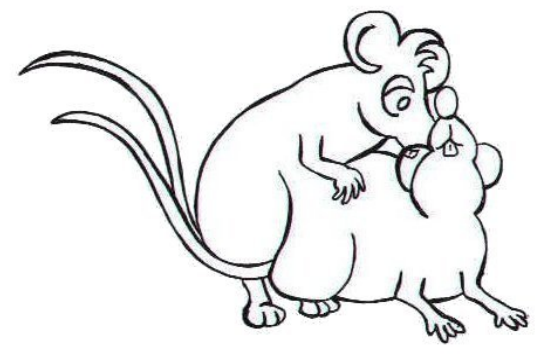

$\mathbf{E}$

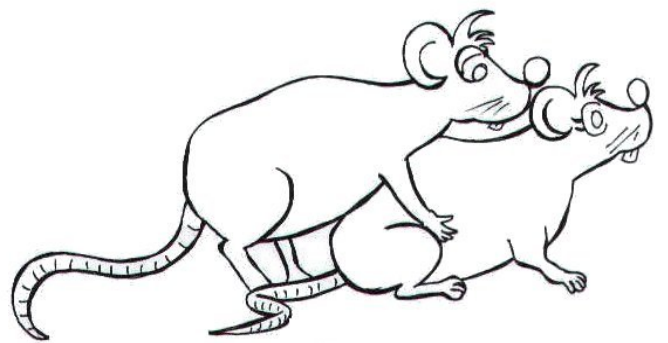

B

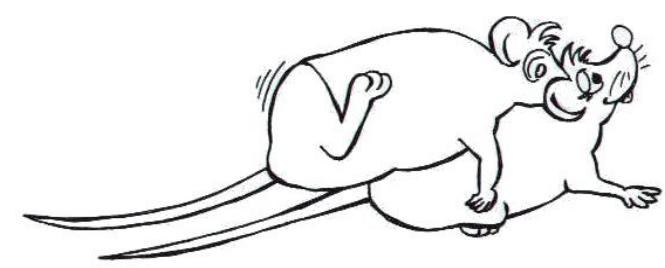

D

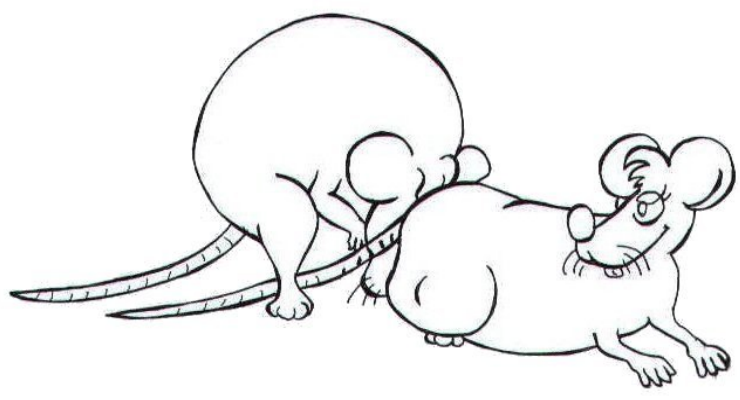

$\mathbf{F}$

Figura 3. Estágios do comportamento sexual de ratos machos conduzindo a uma intromissão. O macho (A) aproxima-se da fêmea, (B) monta e apalpa seu flanco, (C) exibe um empurrão raso da pelve antes da penetração ser realizada, (D) exibe chute alto e intenso de uma ou ambas patas posteriores logo após a penetração, (E) joga-se para fora e para trás da fêmea após uma penetração muito breve, e (F) faz a limpeza da região genital imediatamente após a intromissão. 


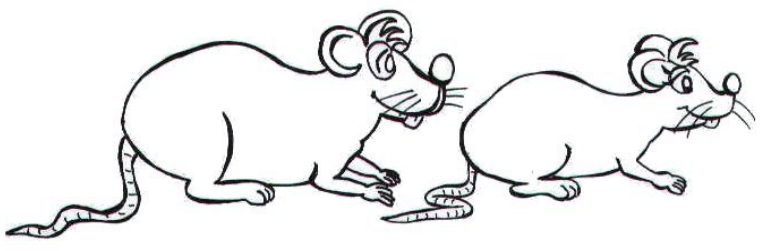

A

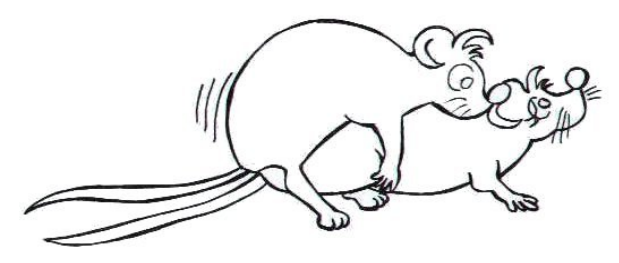

C

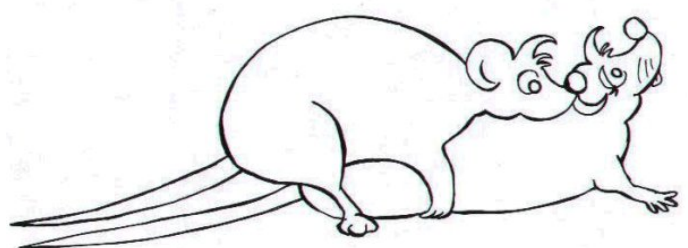

$\mathbf{E}$

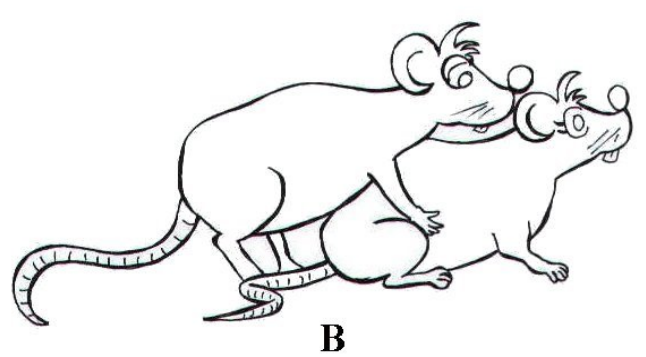

B

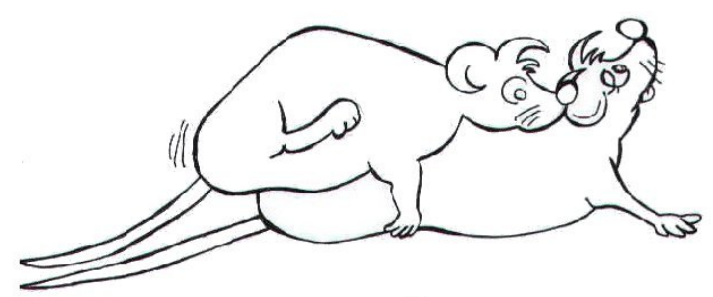

D

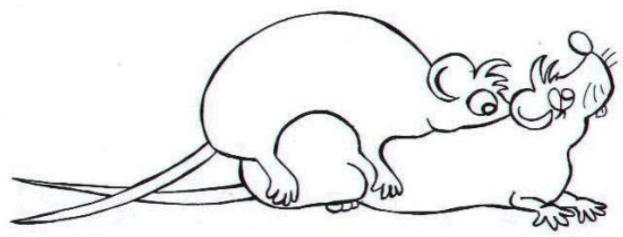

$\mathbf{F}$

Figura 4. Estágios do comportamento sexual de ratos machos conduzindo à ejaculação, após várias intromissões. O macho (A) aproxima-se da fêmea, (B) monta e apalpa seu flanco, (C) exibe um empurrão raso da pelve antes da penetração ser realizada, (D) realiza a penetração e não se joga para trás mas exibe uma flexão ventral forte com chute, somente leve ou moderado, do posterior, (E) apóia-se momentaneamente sobre a fêmea, e (F) cai para o lado ou ergue-se lentamente com os membros anteriores abertos (como “Cristo Redentor”). Logo após a fêmea se afasta e o macho permanece, por um certo período de tempo, alienado ao ambiente (período refratário com duração de 4-8 min) 


\subsection{Análise Estatística}

Foi empregado o software GraphPad Instat v2.01 (GraphPad, 1993) para a realização da análise estatística.

As seguintes análises foram feitas:

- teste de Bartlett para avaliar a homocedasticidade dos dados;

- análise de variância ANOVA para dados paramétricos seguida do teste de múltiplas comparações de Tukey-Kramer para avaliar as possíveis diferenças entre três ou mais grupos (Experimentos 1, 3 e 4);

- teste de Friedman para medidas repetidas, seguido do teste de múltiplas comparações de Dunn para os dados não paramétricos (Experimento 2).

O nível de significância crítico admitido para a rejeição da hipótese de nulidade foi de uma probabilidade de $5 \%(\mathrm{p}<0,05)$ em todas as análises empregadas. 


\section{DELINEAMENTO EXPERIMENTAL E RESULTADOS}

4.1; Experimento 1: Efeitos da administração de moxidectina sobre a atividade geral de ratos observados no campo aberto.

Os ratos foram divididos em 4 grupos iguais de dezesseis animais cada: 1 controle e 3 experimentais. Os animais dos grupos experimentais receberam, por via SC, 0,$2 ; 2,0$ ou 20,0 mg/kg de moxidectina. Os ratos do grupo controle receberam, pela mesma via, $1 \mathrm{ml} / \mathrm{kg}$ de óleo de amêndoas. Posteriormente, às 6, 24, 48 e 72 horas após estas injeções, cada animal foi colocado individualmente no campo aberto, sendo observada a atividade geral, conforme descrito no item 3.3.1.

A Tabela 2 e a Figura 1 mostram os efeitos da administração da moxidectina na atividade geral de ratos observados no campo aberto. Assim, nota-se que não houve diferenças significantes nas freqüências de locomoção $\left(F_{6}=0,14 ; F_{24}=0,90\right.$; $\left.\mathrm{F}_{48}=0,28 ; \quad \mathrm{F}_{72}=0,29 ; \mathrm{df}=3 / 63\right)$, levantar $\left(\mathrm{F}_{6}=0,91 ; \quad \mathrm{F}_{24}=0,94 ; \quad \mathrm{F}_{48}=0,77 ; \quad \mathrm{F}_{72}=1,79 ;\right.$ $d f=3 / 63)$ e defecação $\left(F_{6}=0,96 ; F_{24}=0,37 ; F_{48}=0,29 ; F_{72}=1,35 ; d f=3 / 63\right)$ entre os grupos controle e experimentais. Por outro lado, diferenças significantes entre os grupos foram observadas na duração de imobilidade $\left(F_{6}=0,64 ; F_{24}=1,79 ; F_{48}=0,39\right.$; $\mathrm{F}_{72}=5,23$; $\mathrm{df}=3 / 63$ ); o teste de Tukey-Kramer revelou redução na duração de imobilidade, às 72 horas após a administração de moxidectina, nos grupos de animais que receberam as doses de 0,2 e 20,0 mg/kg, quando comparados com os animais do grupo controle. 
Tabela 2. Efeitos da administração de moxidectina na atividade geral de ratos observados no campo aberto. São apresentadas as médias e os respectivos erros padrões. Número de animais por grupo = 16 .

\begin{tabular}{|c|c|c|c|c|c|}
\hline \multirow[t]{2}{*}{ Parâmetro } & \multirow{2}{*}{$\begin{array}{c}\text { Moxidectina } \\
\text { (mg/kg) }\end{array}$} & \multicolumn{4}{|c|}{ Horas após o tratamento } \\
\hline & & 6 & 24 & 48 & 72 \\
\hline Freqüência & - & $63,0 \pm 5,8$ & $47,9 \pm 7,3$ & $47,0 \pm 8,2$ & $49,6 \pm 10,4$ \\
\hline De & 0,2 & $60,8 \pm 4,5$ & $33,3 \pm 5,7$ & $53,6 \pm 6,6$ & $59,4 \pm 10,4$ \\
\hline \multirow[t]{2}{*}{ locomoção } & 2,0 & $64,6 \pm 8,0$ & $43,6 \pm 7,4$ & $46,1 \pm 8,4$ & $51,1 \pm 8,4$ \\
\hline & 20,0 & $66,4 \pm 6,6$ & $44,4 \pm 6,1$ & $53,8 \pm 7,7$ & $53,9 \pm 7,1$ \\
\hline Freqüência & - & $12,4 \pm 1,2$ & $4,6 \pm 1,0$ & $10,6 \pm 1,7$ & $8,1 \pm 1,7$ \\
\hline De & 0,2 & $14,6 \pm 1,7$ & $5,8 \pm 1,1$ & $10,5 \pm 1,7$ & $13,8 \pm 2,0$ \\
\hline \multirow[t]{2}{*}{ Levantar } & 2,0 & $11,1 \pm 1,6$ & $6,6 \pm 1,2$ & $7,6 \pm 1,2$ & $10,1 \pm 1,7$ \\
\hline & 20,0 & $12,6 \pm 1,5$ & $7,1 \pm 1,1$ & $9,9 \pm 1,8$ & $10,7 \pm 1,6$ \\
\hline Duração & - & $8,7 \pm 3,6$ & $82,9 \pm 15,7$ & $54,9 \pm 16,5$ & $93,8 \pm 19,6$ \\
\hline de & 0,2 & $4,3 \pm 2,4$ & $49,8 \pm 12,2$ & $35,1 \pm 14,2$ & $24,0 \pm 7,4^{*}$ \\
\hline Imobilidade & 2,0 & $15,4 \pm 7,4$ & $49,3 \pm 14,4$ & $39,2 \pm 12,0$ & $51,3 \pm 14,7$ \\
\hline (s) & 20,0 & $17,6 \pm 12,6$ & $42,0 \pm 12,0$ & $39,7 \pm 12,2$ & $33,0 \pm 9,1 *$ \\
\hline \multirow{4}{*}{ Defecação } & - & $1,8 \pm 0,5$ & $1,4 \pm 0,3$ & $1,7 \pm 0,5$ & $1,3 \pm 0,3$ \\
\hline & 0,2 & $3,1 \pm 0,7$ & $1,8 \pm 0,3$ & $1,3 \pm 0,4$ & $1,4 \pm 0,4$ \\
\hline & 2,0 & $2,4 \pm 0,5$ & $1,8 \pm 0,6$ & $1,9 \pm 0,5$ & $1,9 \pm 0,4$ \\
\hline & 20,0 & $2,6 \pm 0,6$ & $2,1 \pm 0,6$ & $1,8 \pm 0,5$ & $2,3 \pm 0,4$ \\
\hline
\end{tabular}

* $\mathrm{p}<0,05$, ANOVA seguida de Tukey-Kramer 


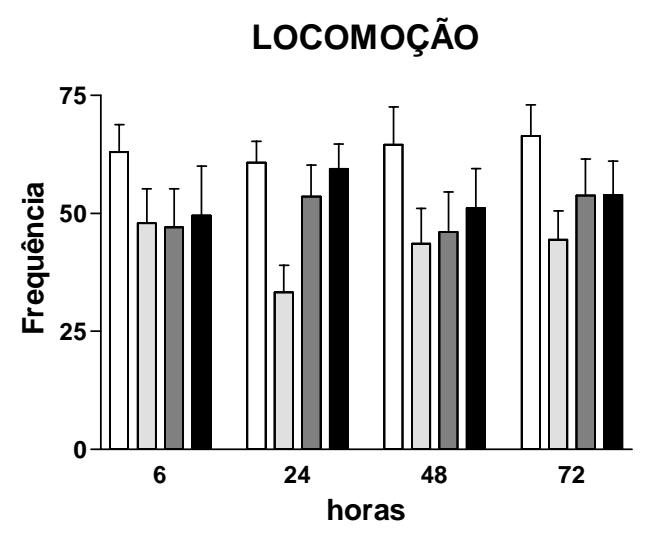

IMOBILIDADE

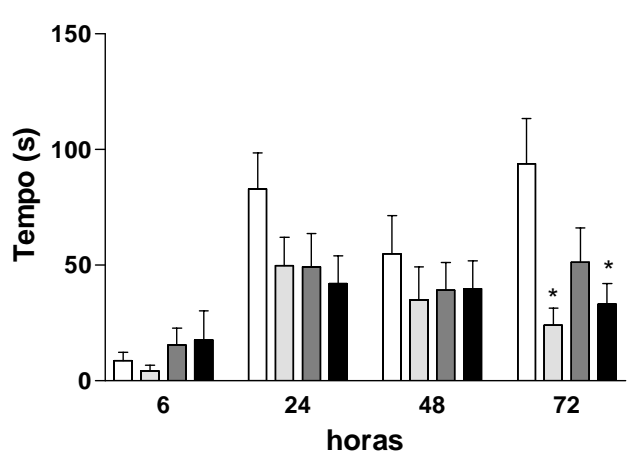

LEVANTAR

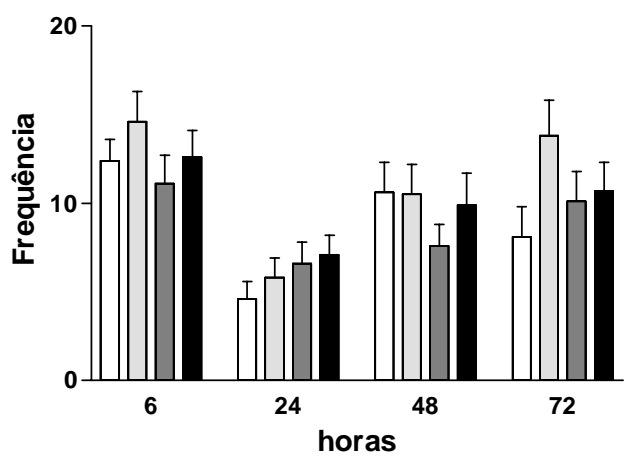

DEFECAÇÃO

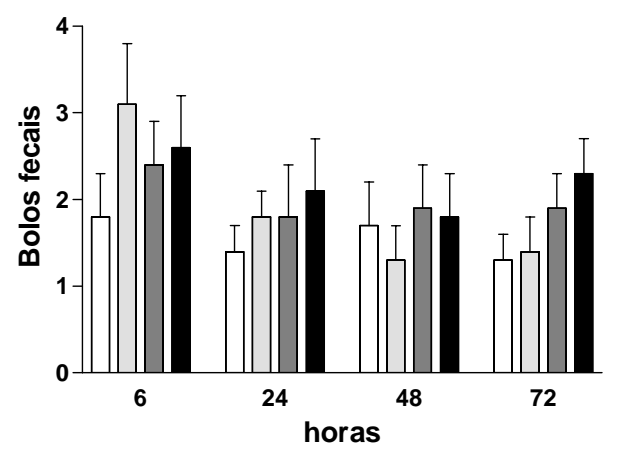

$\square$ controle

$\square$ Mox 0,2 mg/kg

$\square$ Mox 2,0 mg/kg

Mox 20,0 mg/kg

FIGURA 1. Efeitos da administração de Moxidectina na atividade geral de ratos observados no campo aberto. As diferentes figuras representam os seguintes parâmetros: freqüência de locomoção e levantar, duração de imobilidade (s), e defecação. São apresentadas as médias e respectivos erros padrões. $\left(^{*}\right) \mathrm{p}<0,05$, ANOVA seguida de Tukey-Kramer. 
4.2. Experimento 2: Avaliação na trave elevada da coordenação motora de ratos tratados com moxidectina.

Foram usados 30 ratos machos treinados na trave elevada. A seguir, os ratos foram divididos em três grupos iguais e submetidos a 5 sessões de observação na trave, sendo atribuídos escores ao seu desempenho, conforme descrito no item 3.3.2. A primeira sessão foi realizada 24 horas antes da administração das diferentes doses de moxidectina (0,2; 2,0 e 20,0 mg/kg) e as demais às 6, 24, 48 e 72 horas após.

A tabela 3 a Figura 2 mostram os efeitos da moxidectina na coordenação motora de ratos avaliados na trave elevada. Assim, nota-se que houve um aumento na soma dos escorres às 6 , 48 e 72 h após a administração de $0,2 \mathrm{mg} / \mathrm{kg}$ de moxidectina e também às 24, 48 e 72 h após a administração de 2,0 e 20,0 mg/kg da droga, quando comparadas à soma dos escores obtidos 24 horas antes da injeção. 
Tabela 3. Efeitos da moxidectina na coordenação motora de ratos avaliados na trave elevada. As sessões foram realizadas 24 h antes e 6, 24, 48 e 72 h após a administração das diferentes doses da droga. São apresentadas as medianas da soma dos escores obtidos em cada sessão e os respectivos limites. Número de animais por grupo $=10$

\begin{tabular}{cccccc}
\hline \multirow{2}{*}{$\begin{array}{c}\text { Moxidectina } \\
\text { (mg/kg) }\end{array}$} & $-24 \mathrm{~h}$ & $6 \mathrm{~h}$ & $24 \mathrm{~h}$ & $48 \mathrm{~h}$ & $72 \mathrm{~h}$ \\
\cline { 2 - 6 } & & & & \\
& 5,0 & $10,5^{*}$ & 8,5 & $12,5^{*}$ & $9,5^{*}$ \\
0,2 & $(1,0-6,0)$ & $(4,0-16,0)$ & $(4,0-16,0)$ & $(9,0-19,0)$ & $(5,0-22,0)$ \\
& & & & & \\
2,0 & & & & & $13,0^{*}$ \\
& $(3,0-8,0)$ & $(9,0-19,0)$ & $(9,0-17,0)$ & $(10,0-21,0)$ & $(10,0-22,0)$ \\
& & & & & $15,0^{*}$ \\
20,0 & 5,0 & 9.0 & $10.0^{*}$ & $11.0^{*}$ & $13.0^{*}$ \\
& $(0-8,0)$ & $(2,0-11,0)$ & $(4,0-16,0)$ & $(3,0-19,0)$ & $(9,0-19,0)$
\end{tabular}

${ }^{*} \mathrm{p}<0,05$, teste de Friedman seguido do teste de Dunn (em relação a -24h). 


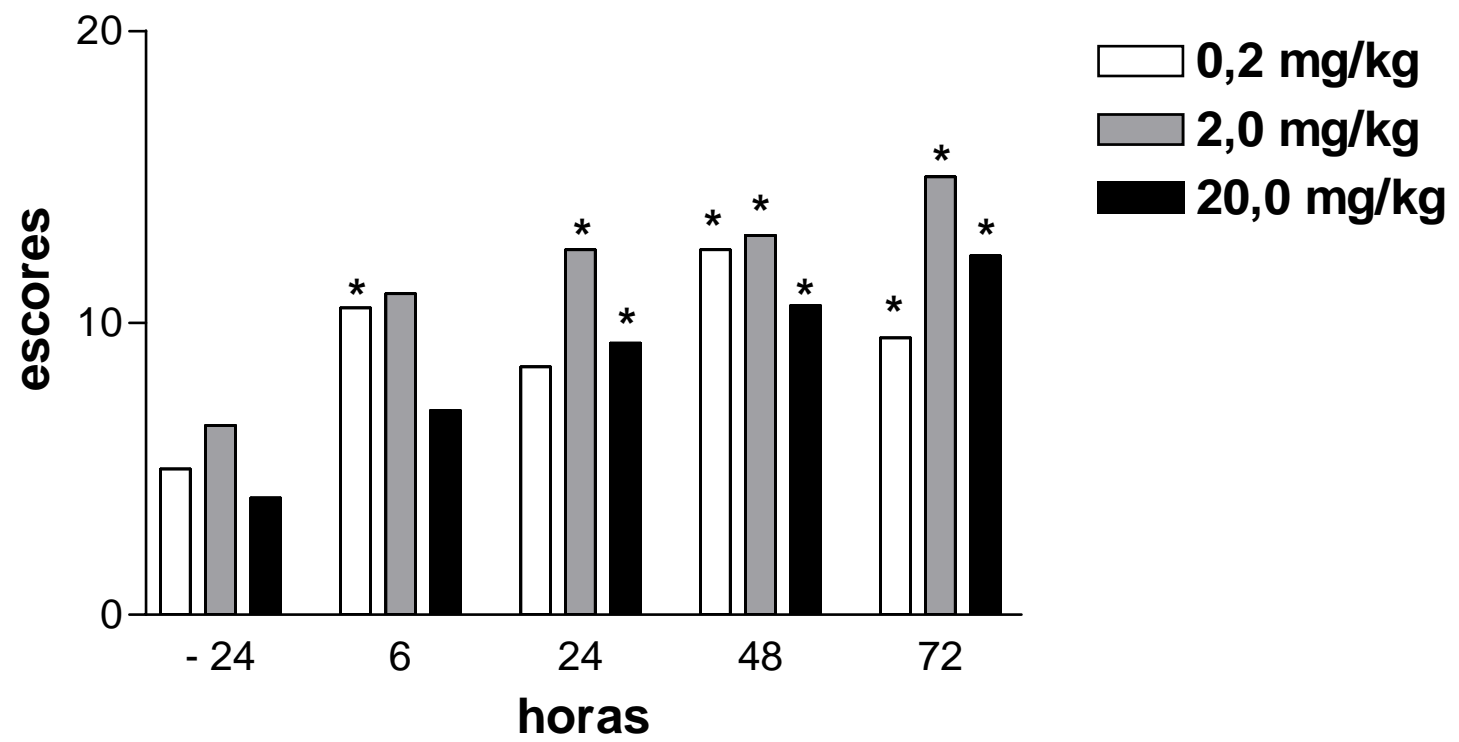

FIGURA 2. Efeitos da moxidectina na coordenação motora de ratos avaliados na trave elevada. São apresentadas as medianas da soma dos escores obtidos $24 \mathrm{~h}$ antes e 6, 24, 48, e 72 h após a administração da droga. * p < 0,05, teste de medidas repetidas de Friedman, seguido do teste de Dunn (em relação à - 24 h). 
4.3. Experimento 3: Efeitos da moxidectina no comportamento sexual de ratos machos ingênuos.

Foram utilizados 54 ratos machos que nunca haviam tido contato sexual com fêmeas (ratos ingênuos), os quais foram alojados em sala com ciclo de luz parcialmente invertido por, no mínimo, um mês antes do início do experimento. Estes animais foram divididos em 5 grupos: 1 controle e 4 experimentais. Os ratos de três grupos experimentais receberam, respectivamente, 0,2; 2,0 e 20,0 mg/kg de moxidectina, sendo o comportamento sexual avaliado após 24 horas e o quarto grupo experimental recebeu $0,2 \mathrm{mg} / \mathrm{kg}$ da droga e foi observado após 72 h. Os ratos do grupo controle receberam 0,1 ml/kg de óleo de amêndoas, sendo observados após 24 h, conforme descrito no item 3.3.3.

A tabela 4 e as Figuras 3, 4 e 5 mostram os efeitos da administração de moxidectina no comportamento sexual de ratos machos ingênuos. A ANOVA revelou diferenças significantes entre os grupos apenas nas latências para $1^{\mathrm{a}}$ monta $(\mathrm{F}=6,06 ; \mathrm{df}=2 / 24)$ e para $1^{\mathrm{a}}$ intromissão $(\mathrm{F}=5,41 ; \mathrm{df}=2 / 24)$ e no número total de montas incompletas e intromissões nos $40 \mathrm{~min}(\mathrm{~F}=4,65$; $\mathrm{df}=2 / 30)$. O teste de TukeyKramer mostrou que $0,2 \mathrm{mg} / \mathrm{kg}$ de moxidectina aumentou as latências para $1^{\mathrm{a}}$ monta e para $1^{\mathrm{a}}$ intromissão do grupo observado 72 h após a administração da droga, quando comparado com o grupo controle, e a latência para $1^{\mathrm{a}}$ intromissão também aumentou em relação ao grupo observado às 24 h; esta mesma dose da droga reduziu o número total de montas incompletas e intromissões dos ratos tanto aqueles observados 24 como 72 h após a administração da moxidectina. 
Tabela 4. Efeitos da moxidectina (Mox) em parâmetros do comportamento sexual de ratos ingênuos observados 24 ou 72 horas após administração da droga. São apresentadas as médias e os respectivos erros padrões. $\mathrm{N}$ = número de animais

GRUPOS

\begin{tabular}{|c|c|c|c|c|c|}
\hline \multirow[b]{3}{*}{ PARÂMETROS } & \multirow{2}{*}{\multicolumn{4}{|c|}{24 horas }} & \multirow{3}{*}{$\begin{array}{c}72 \text { horas } \\
\text { Mox 0,2 } \\
\mathrm{mg} / \mathrm{kg} \\
(\mathrm{N}=10)\end{array}$} \\
\hline & & & & & \\
\hline & $\begin{array}{l}\text { Controle } \\
(\mathrm{N}=9)\end{array}$ & $\begin{array}{c}\text { Mox 0,2 } \\
\mathrm{mg} / \mathrm{kg} \\
(\mathrm{N}=11) \\
\end{array}$ & $\begin{array}{c}\text { Mox 2,0 } \\
\mathrm{mg} / \mathrm{kg} \\
(\mathrm{N}=10)\end{array}$ & $\begin{array}{c}\text { Mox 20,0 } \\
\mathrm{mg} / \mathrm{kg} \\
(\mathrm{N}=10)\end{array}$ & \\
\hline $\begin{array}{l}\text { Latência para } 1^{\text {a }} \text { monta } \\
\text { (min) }\end{array}$ & $1,1 \pm 0,2$ & $1,1 \pm 0,3$ & $1,3 \pm 0,3$ & $1,7 \pm 0,5$ & $2,8 \pm 0,6^{*}$ \\
\hline $\begin{array}{l}\text { Latência para } 1^{\text {a }} \\
\text { intromissão (min) }\end{array}$ & $1,4 \pm 0,2$ & $1,3 \pm 0,4$ & $1,4 \pm 0,3$ & $2,1 \pm 0,5$ & $3,0 \pm 0,6^{*}$ \\
\hline $\begin{array}{l}\text { Latência para } 1^{\text {a }} \\
\text { ejaculação (min) }\end{array}$ & $18,9 \pm 2,8$ & $15,6 \pm 2,0$ & $17,9 \pm 8,6$ & $17,3 \pm 3,2$ & $21,7 \pm 2,7$ \\
\hline $\begin{array}{l}\mathrm{N}^{\circ} \text { intromissões até } \\
\text { a } 1^{\mathrm{a}} \text { ejaculação }\end{array}$ & $31,8 \pm 5,0$ & $22,7 \pm 3,6$ & $25,4 \pm 2,5$ & $26,8 \pm 6,0$ & $20,8 \pm 2,0$ \\
\hline $\begin{array}{l}\mathrm{N}^{\circ} \text { montas incompletas } \\
\text { até a } 1^{\text {a }} \text { ejaculação }\end{array}$ & $12,4 \pm 1,5$ & $12,4 \pm 2,5$ & $13,1 \pm 1,9$ & $14,8 \pm 3,3$ & $13,6 \pm 2,7$ \\
\hline $\begin{array}{l}\text { Total de montas incompletas } \\
\text { e intromissões até a } 1^{\text {a }} \\
\text { ejaculação }\end{array}$ & $44,2 \pm 5,9$ & $38,3 \pm 7,0$ & $39,6 \pm 4,0$ & $39,7 \pm 8,7$ & $35,7 \pm 4,8$ \\
\hline $\begin{array}{l}\text { Total de montas incompletas } \\
\text { e intromissões nos } 40 \text { min }\end{array}$ & $74,8 \pm 6,9$ & $52,7 \pm 6,3^{*}$ & $60,1 \pm 8,0$ & $64,5 \pm 6,0$ & $51,9 \pm 4,2^{*}$ \\
\hline $\begin{array}{l}\text { Latência para } 1^{\mathrm{a}} \text { monta } \\
\text { após a } 1^{\mathrm{a}} \text { ejaculação (min) }\end{array}$ & $4,2 \pm 0,4$ & $4,6 \pm 0,4$ & $5,2 \pm 0,3$ & $4,6 \pm 0,2$ & $5,3 \pm 0,3$ \\
\hline $\begin{array}{l}\text { Latência p/ 1 }{ }^{\mathrm{a}} \text { intromissão } \\
\text { após a } 1^{\mathrm{a}} \text { ejaculação (min) }\end{array}$ & $4,2 \pm 0,4$ & $4,7 \pm 0,4$ & $5,3 \pm 0,3$ & $4,8 \pm 0,3$ & $5,3 \pm 0,3$ \\
\hline $\mathrm{N}^{\mathrm{o}}$ de ejaculações & $2,1 \pm 0,5$ & $1,7 \pm 0,5$ & $1,8 \pm 0,4$ & $2,2 \pm 0,5$ & $1,6 \pm 0,3$ \\
\hline $\begin{array}{l}\text { Freqüência de montas por } \\
\text { minuto }\end{array}$ & $2,4 \pm 0,2$ & $1,9 \pm 0,4$ & $2,3 \pm 0,6$ & $2,2 \pm 0,2$ & $1,7 \pm 0,2$ \\
\hline $\begin{array}{l}\text { Freqüência de intromissões } \\
\text { por minuto }\end{array}$ & $1,5 \pm 0,2$ & $1,2 \pm 0,2$ & $1,4 \pm 0,3$ & $1,6 \pm 0,1$ & $1,1 \pm 0,2$ \\
\hline $\begin{array}{c}\text { Intervalo inter- } \\
\text { intromissões (min) }\end{array}$ & $0,6 \pm 0,1$ & $0,8 \pm 0,1$ & $0,7 \pm 0,1$ & $0,7 \pm 0,1$ & $1,0 \pm 0,1$ \\
\hline $\begin{array}{l}\text { Eficiência copulatória } \\
(\%)\end{array}$ & $70 \pm 3,3$ & $66 \pm 1,1$ & $65 \pm 2,2$ & $70 \pm 2,5$ & $64 \pm 2,8$ \\
\hline Índice de atividade sexual & $14,6 \pm 1,2$ & $13,1 \pm 1,2$ & $14,0 \pm 1,4$ & $14,9 \pm 0,5$ & $13,4 \pm 0,6$ \\
\hline $\begin{array}{l}\text { Freqüência de ejaculação } \\
(\%)\end{array}$ & 81,8 & 63,6 & 80,0 & 90,0 & 90,0 \\
\hline
\end{tabular}

${ }^{*} \mathrm{p}<0,05$, ANOVA seguida do teste de Tukey-Kramer. 
$1^{\text {a }}$ Monta

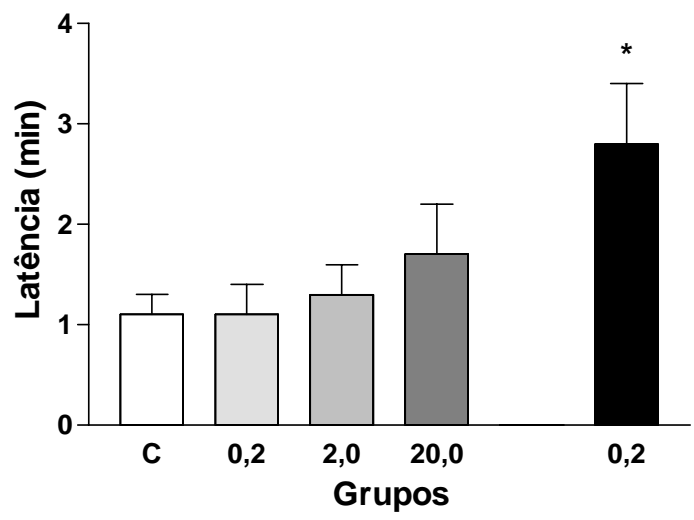

$1^{\text {a }}$ Intromissão

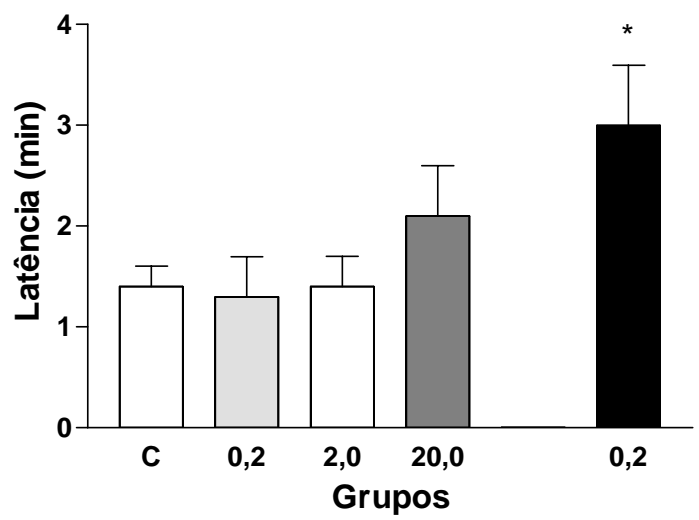

$1^{\text {a Ejaculação }}$

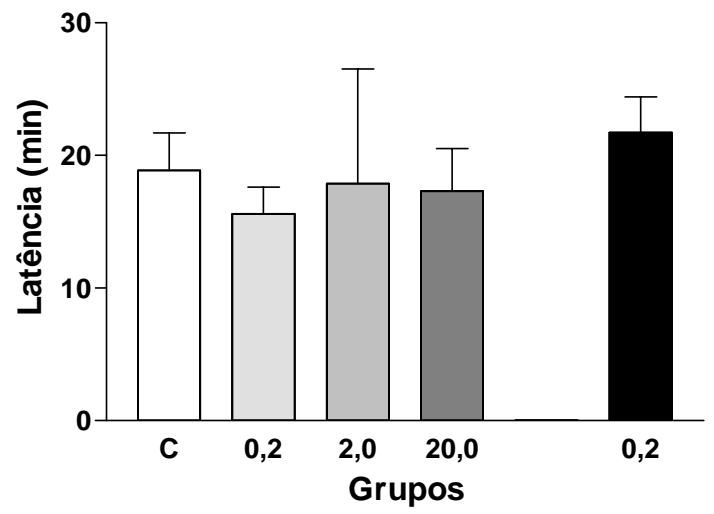

$\square$ Controle

$\square$ Mox 0,2 mg/kg (24 h)

$\square$ Mox 2,0 mg/kg (24 h)

$\square$ Mox 20,0mg/kg (24 h)

Mox 0,2 mg/kg (72 h)

1ª Monta Pós-ejaculação

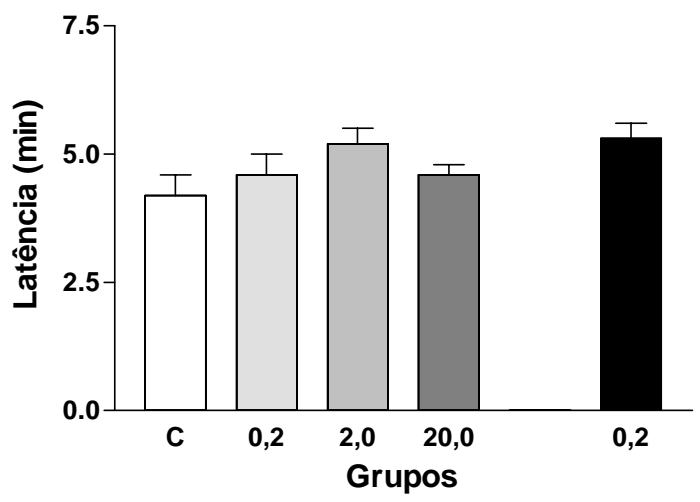

$1^{\text {a }}$ Intromissão Pós-ejaculação

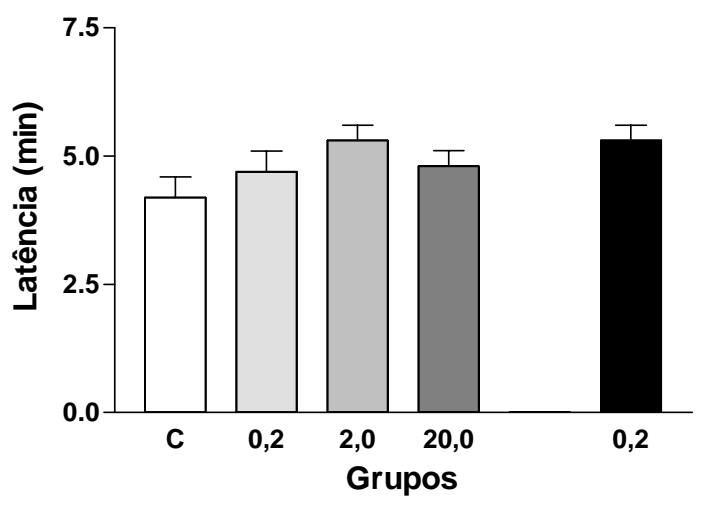

Figura 3. Efeitos da moxidectina $(0,2 ; 2,0 ;$ ou $20,0 \mathrm{mg} / \mathrm{kg})$ nas latências de parâmetros do comportamento sexual de ratos ingênuos, observados 24 ou 72 horas após a administração. São representadas as médias e respectivos erros padrões. C grupo controle. $\mathrm{p}<0,05$, ANOVA seguida do teste de Tukey-Kramer. 


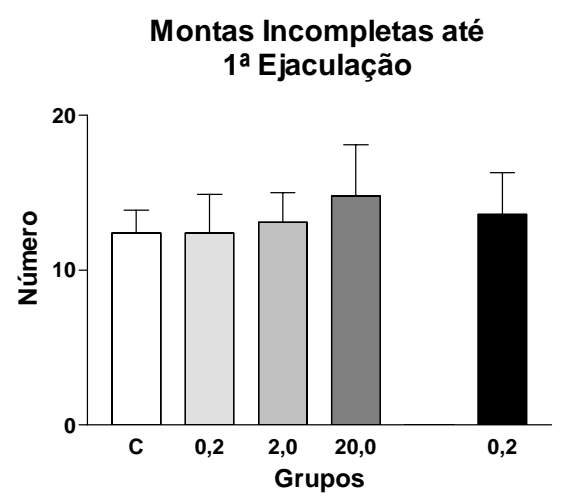

Montas Incompletas e Intromissões até $1^{\mathrm{a}}$ ejaculação

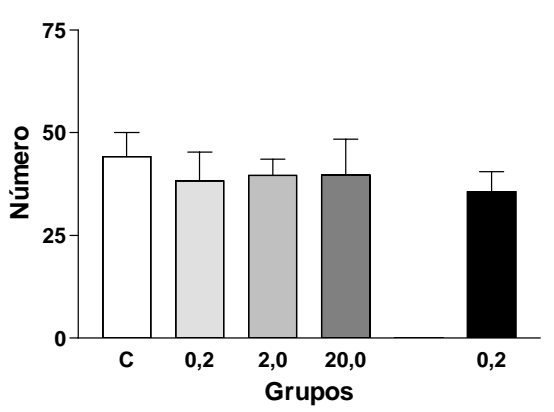

Intromissões até $1^{a}$ Ejaculação

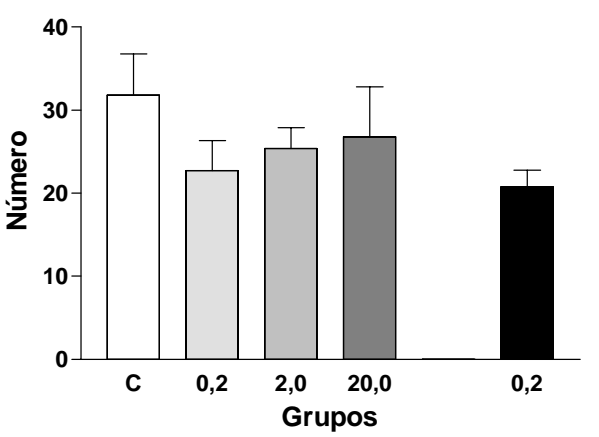

Total de Ejaculações

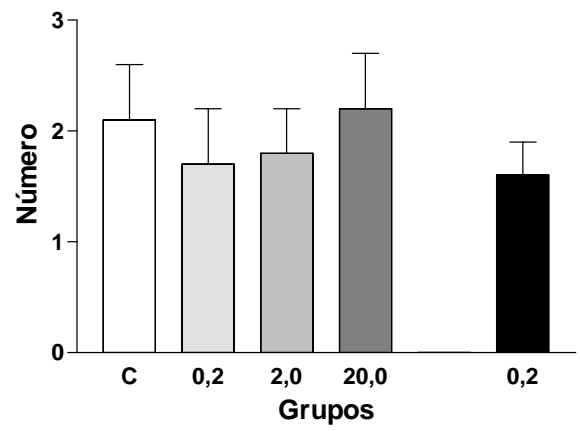

Total de Montas

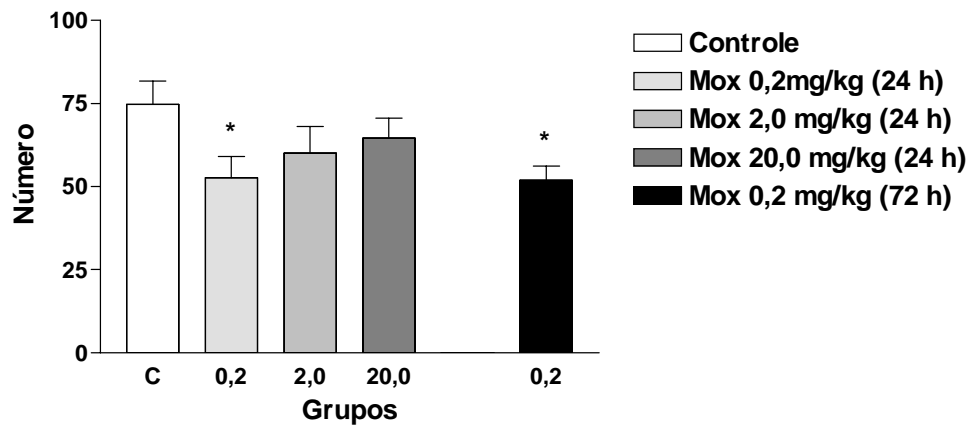

Figura 4. Efeitos da moxidectina $(0,2 ; 2,0 ;$ ou $20,0 \mathrm{mg} / \mathrm{kg})$ em parâmetros do comportamento sexual de ratos ingênuos, observados 24 ou 72 horas após a administração. São representadas as médias e respectivos erros padrões do número de montas incompletas e/ou de intromissões até a $1^{\text {a }}$ ejaculação, e número de ejaculações e de montas incompletas e intromissões no tempo total de observação. C - grupo controle.

* $\mathrm{p}<0,05$, ANOVA seguida do teste de Tukey-Kramer. 

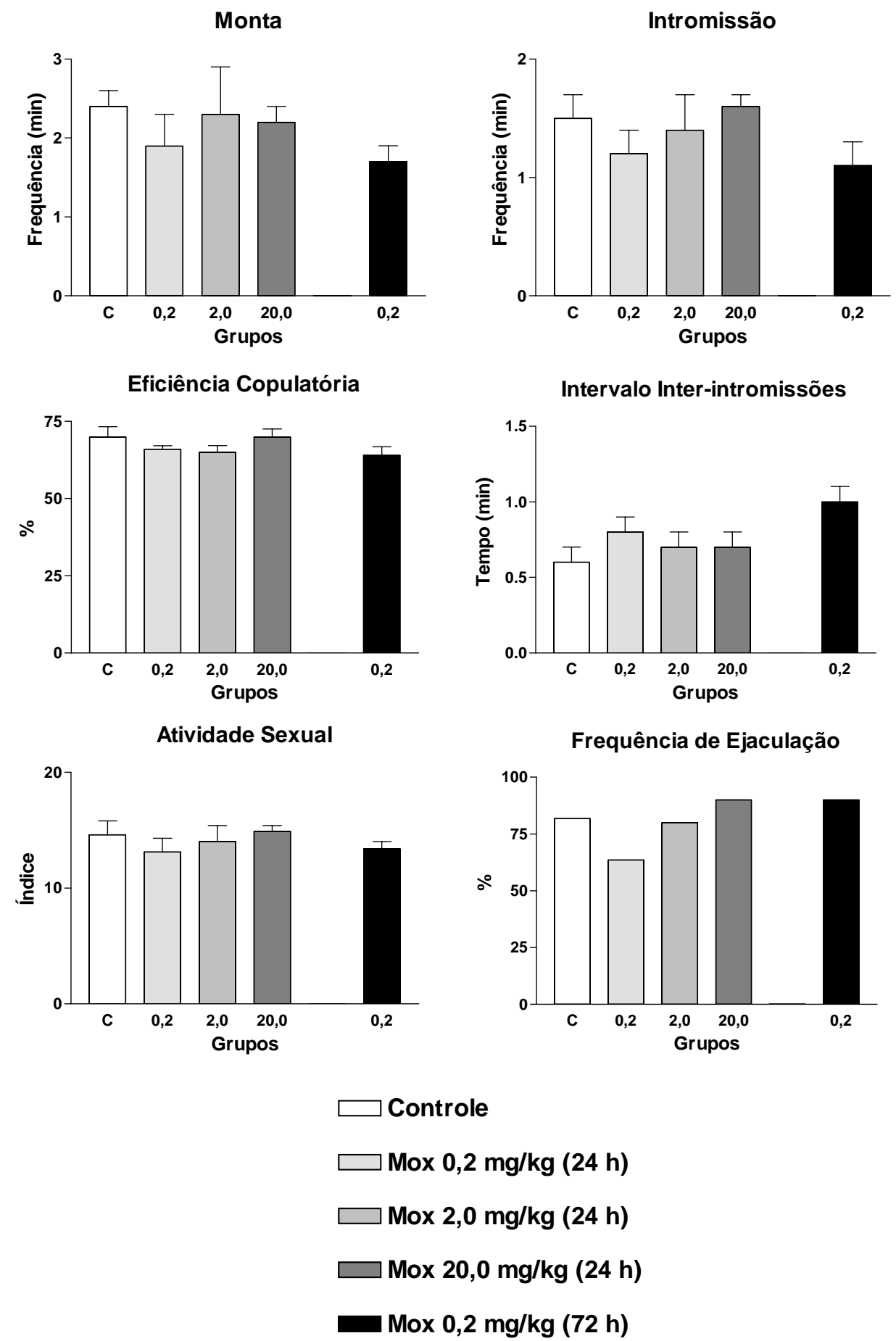

Figura 5. Efeito da Moxidectina (0,2; 2,0; ou 20,0 mg/kg) em índices do comportamento sexual de ratos ingênuos. São apresentadas as médias e respectivos erros padrões.

$\mathrm{C}$ - grupo controle. $\mathrm{p}>0,05$, ANOVA. 
4.4. Experimento 4: Efeitos da moxidectina no comportamento sexual de ratos machos experientes.

Foram utilizados ratos machos alojados em sala com ciclo de luz parcialmente invertido por, no mínimo, um mês antes do início do experimento. Após este período foram individualmente colocados na presença de fêmeas receptivas (iscas) e seu comportamento sexual foi observado até o fim do primeiro período refratário (até a primeira intromissão após a primeira ejaculação) ou por até 40 minutos contados a partir da primeira intromissão. Isto foi feito para que os animais se tornassem sexualmente experientes. O animal que após este período de observação não ejaculou, foi avaliado por mais duas vezes, com intervalos de $72 \mathrm{~h}$ entre as observações, até ejacular, e caso isto não tenha ocorrido, foi eliminado do experimento.

Uma vez experientes, 39 ratos machos foram divididos em quatro grupos; dois grupos controles receberam $0,1 \mathrm{ml} / \mathrm{kg}$ de óleo de amêndoas, e dois grupos experimentais receberam $0,2 \mathrm{mg} / \mathrm{kg}$ de moxidectina. Um grupo controle e um experimental foram observados às 24 h e os outros dois às 72 h após as injeções. $\mathrm{O}$ comportamento sexual foi avaliado por $40 \mathrm{~min}$, conforme descritos no item 3.3.3.

A Tabela 5 e as Figuras 6, 7 e 8 mostram os efeitos da administração de moxidectina no comportamento sexual de ratos machos experientes. A ANOVA não revelou diferenças significantes entre os grupos para nenhum dos parâmetros avaliados. 
Tabela 5. Efeitos da moxidectina (Mox) em parâmetros do comportamento sexual de ratos experientes observados 24 ou 72 horas após administração da droga. São apresentadas as médias e os respectivos erros padrões. $\mathrm{N}$ = número de animais

\begin{tabular}{|c|c|c|c|c|}
\hline \multirow{3}{*}{ PARÂMETROS } & \multicolumn{4}{|c|}{ GRUPOS } \\
\hline & \multicolumn{2}{|c|}{24 HORAS } & \multicolumn{2}{|c|}{72 HORAS } \\
\hline & $\begin{array}{l}\text { Controle } \\
(\mathrm{N}=10)\end{array}$ & $\begin{array}{c}\text { Mox 0,2 } \\
\mathrm{mg} / \mathrm{kg} \\
(\mathrm{N}=10)\end{array}$ & $\begin{array}{l}\text { Controle } \\
(\mathrm{N}=9)\end{array}$ & $\begin{array}{c}\text { Mox 0,2 } \\
\mathrm{mg} / \mathrm{kg} \\
(\mathrm{N}=10)\end{array}$ \\
\hline Latência para $1^{\mathrm{a}}$ monta (min) & $0,2 \pm 0,09$ & $0,3 \pm 0,15$ & $0,2 \pm 0,02$ & $0,1 \pm 0,02$ \\
\hline $\begin{array}{c}\text { Latência para } 1^{\mathrm{a}} \text { intromissão } \\
(\mathrm{min})\end{array}$ & $0,3 \pm 0,1$ & $0,4 \pm 0,1$ & $0,2 \pm 0,03$ & $0,2 \pm 0,02$ \\
\hline $\begin{array}{c}\text { Latência para } 1^{\mathrm{a}} \text { ejaculação } \\
(\mathrm{min})\end{array}$ & $13,6 \pm 1,2$ & $14,8 \pm 2,1$ & $18,7 \pm 3,5$ & $16,8 \pm 2,61$ \\
\hline $\begin{array}{c}\mathrm{N}^{\mathrm{o}} \text { de montas incompletas até } \\
\text { a } 1^{\mathrm{a}} \text { ejaculação }\end{array}$ & $13,5 \pm 1,8$ & $14,2 \pm 3,5$ & $19,4 \pm 3,2$ & $16,3 \pm 3,1$ \\
\hline $\begin{array}{c}\mathrm{N}^{0} \text { de intromissões até a } 1^{\mathrm{a}} \\
\text { ejaculação }\end{array}$ & $24,1 \pm 2,0$ & $27,1 \pm 4,4$ & $33,3 \pm 3,8$ & $30,9 \pm 3,3$ \\
\hline $\begin{array}{l}\mathrm{N}^{\circ} \text { total de montas incompletas e } \\
\text { intromissões até a } 1^{\mathrm{a}} \text { ejaculação }\end{array}$ & $37,6 \pm 3,3$ & $41,3 \pm 7,8$ & $52,8 \pm 6,6$ & $47,3 \pm 5,9$ \\
\hline $\begin{array}{l}\mathrm{N}^{\circ} \text { total de montas incompletas e } \\
\text { intromissões nos } 40 \mathrm{~min}\end{array}$ & $65,4 \pm 6,1$ & $71,1 \pm 6,8$ & $80,9 \pm 4,6$ & $79,4 \pm 5,6$ \\
\hline $\begin{array}{c}\text { Latência para } 1^{\mathrm{a}} \text { monta após a } \\
1^{\mathrm{a}} \text { ejaculação (min) }\end{array}$ & $4,7 \pm 0,2$ & $5,2 \pm 0,2$ & $4,5 \pm 0,1$ & $5,1 \pm 0,2$ \\
\hline $\begin{array}{l}\text { Latência p/ } 1^{\mathrm{a}} \text { intromissão } \\
\text { após a } 1^{\mathrm{a}} \text { ejaculação (min) }\end{array}$ & $4,7 \pm 0,2$ & $5,2 \pm 0,2$ & $4,6 \pm 0,1$ & $5,1 \pm 0,2$ \\
\hline $\mathrm{N}^{\mathrm{o}}$ de ejaculações & $3,40 \pm 0,3$ & $2,60 \pm 0,27$ & $2,56 \pm 0,44$ & $2,60 \pm 0,31$ \\
\hline $\begin{array}{l}\text { Freqüência de montas por } \\
\text { minuto }\end{array}$ & $2,9 \pm 0,3$ & $3,1 \pm 0,3$ & $3,2 \pm 0,3$ & $3,0 \pm 0,2$ \\
\hline $\begin{array}{l}\text { Freqüência de intromissões } \\
\text { por minuto }\end{array}$ & $1,9 \pm 0,2$ & $1,9 \pm 0,2$ & $2,0 \pm 0,2$ & $2,1 \pm 0,2$ \\
\hline $\begin{array}{l}\text { Intervalo inter intromissões } \\
\text { (min) }\end{array}$ & $0,6 \pm 0,06$ & $0,6 \pm 0,04$ & $0,5 \pm 0,05$ & $0,5 \pm 0,05$ \\
\hline $\begin{array}{c}\text { Eficiência copulatória } \\
(\%)\end{array}$ & $65,3 \pm 2,7$ & $67,5 \pm 1,9$ & $64,3 \pm 2,0$ & $67,7 \pm 3,2$ \\
\hline Índice de atividade sexual & $17,3 \pm 0,4$ & $17,3 \pm 0,4$ & $18,2 \pm 0,3$ & $18,3 \pm 0,4$ \\
\hline $\begin{array}{c}\text { Freqüência de ejaculação } \\
(\%)\end{array}$ & 100 & 100 & 100 & 100 \\
\hline
\end{tabular}

$\mathrm{p}>0,05$, ANOVA 
$1^{\mathrm{a}}$ Monta

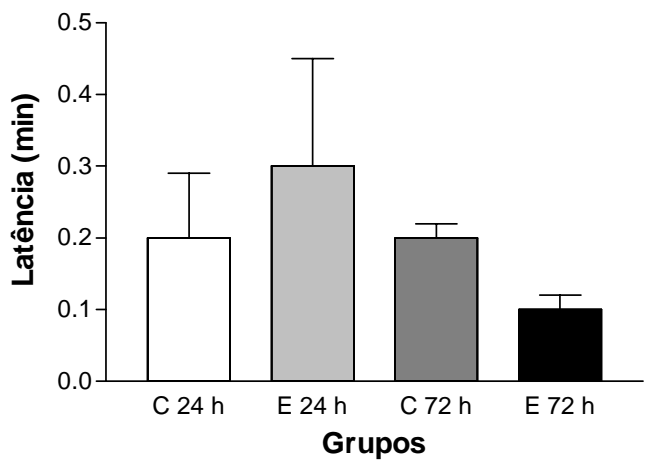

$1^{\mathrm{a}}$ Intromissão

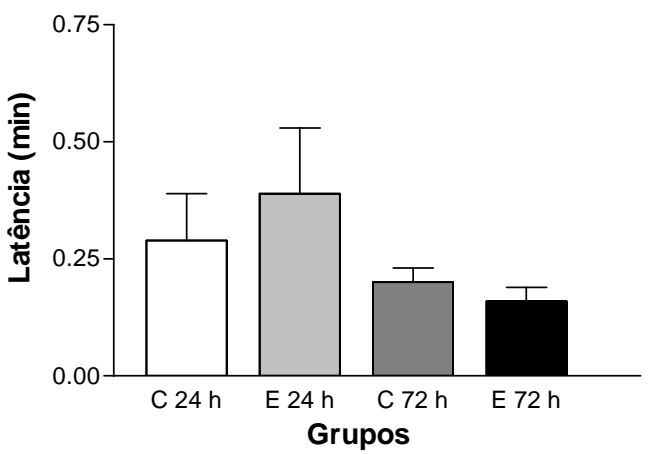

$1^{\text {a Ejaculação }}$

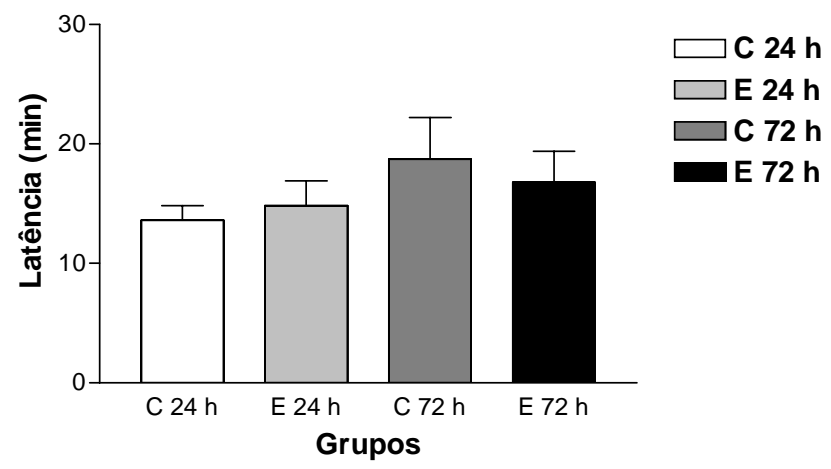

$1^{\text {a }}$ Monta Pós-ejaculação

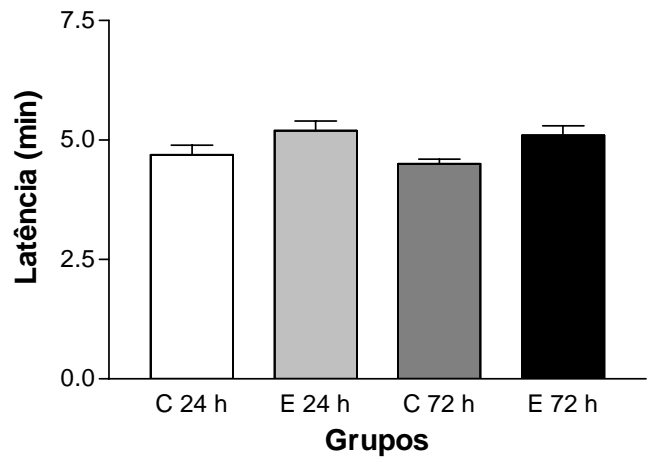

$1^{\text {a }}$ Intromissão Pós-ejaculação

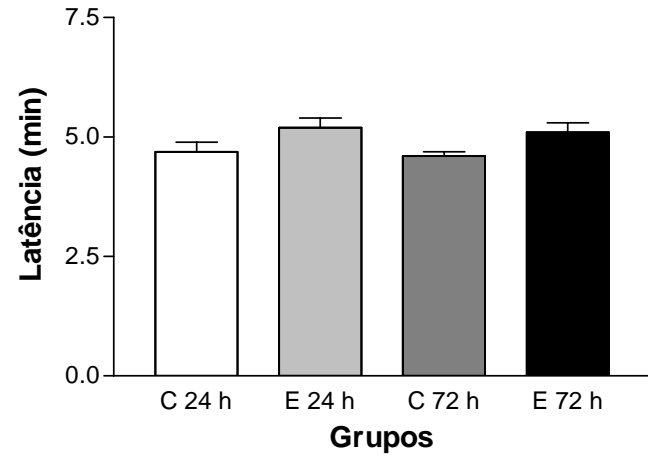

Figura 6. Efeitos da moxidectina $(0,2 \mathrm{mg} / \mathrm{kg})$ nas latências de parâmetros do comportamento sexual de ratos experientes, observados 24 ou 72 horas após a administração. São representadas as médias e respectivos erros padrões. C - grupo controle, E - grupo experimental. $\mathrm{p}>0,05$, ANOVA. 

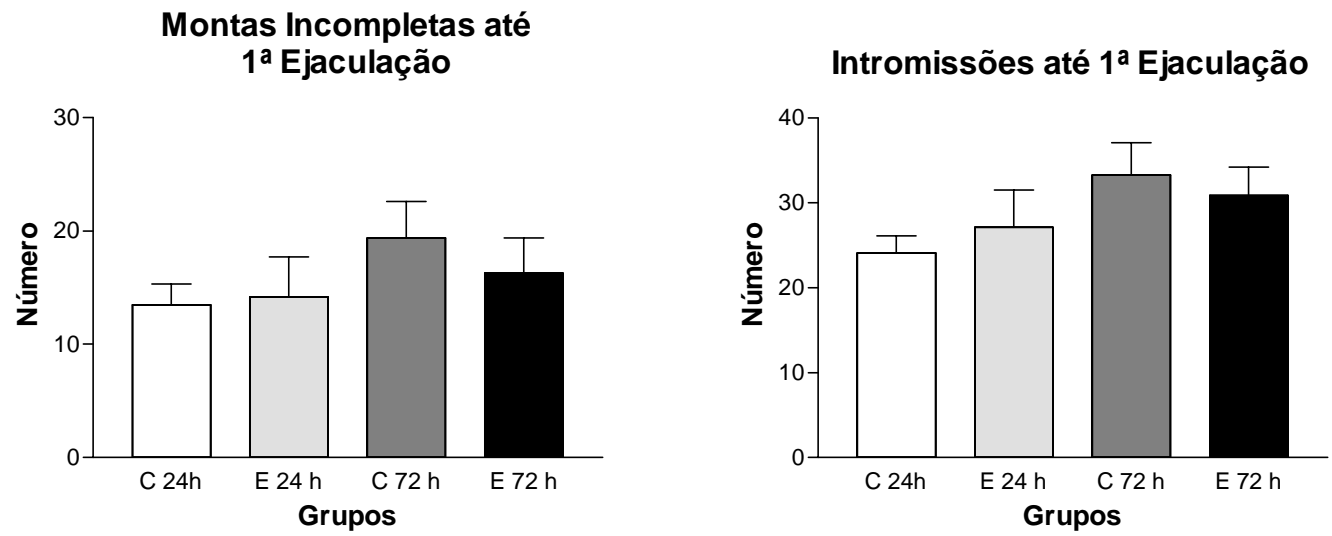

Total de Montas até

$1^{a}$ Ejaculação

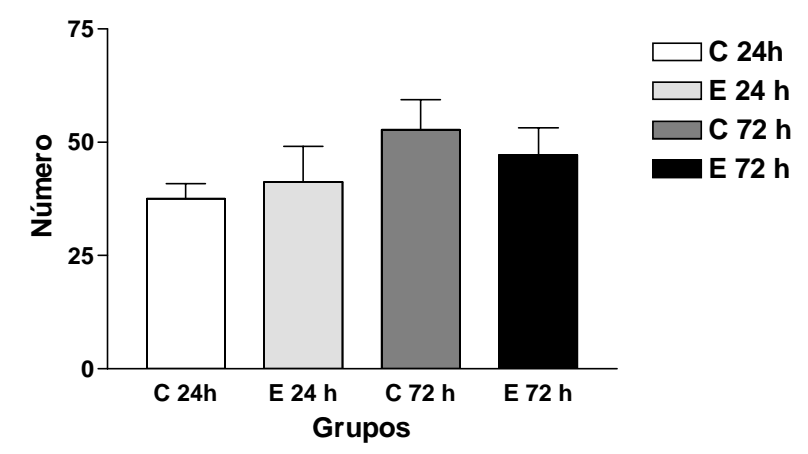

Total de Montas

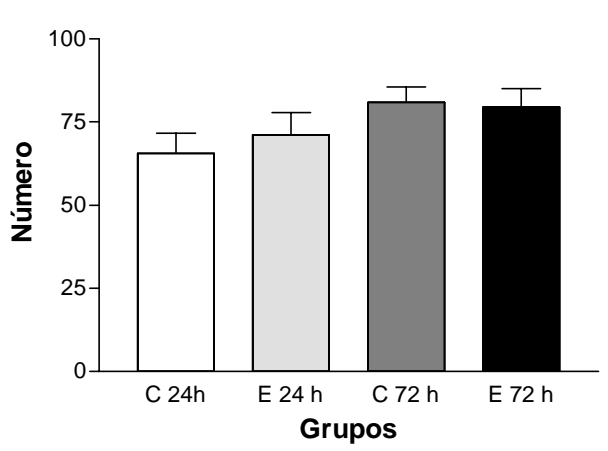

Total de Ejaculações

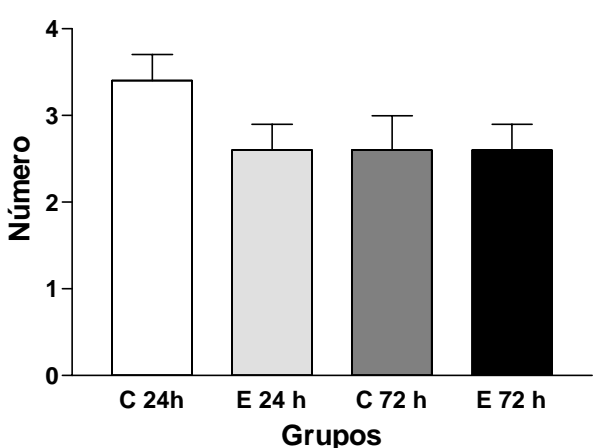

Figura 7. Efeitos da moxidectina $(0,2 \mathrm{mg} / \mathrm{kg})$ em parâmetros do comportamento sexual de ratos experientes, observados 24 ou 72 horas após a administração. São representadas as médias e respectivos erros padrões do número de montas incompletas e/ou de intromissões até a $1^{\mathrm{a}}$ ejaculação, e número de ejaculações e de montas incompletas e intromissões no tempo total de observação. C - grupo controle, $\mathrm{E}$ - grupo experimental. $\mathrm{p}>0,05$, ANOVA. 
Montas

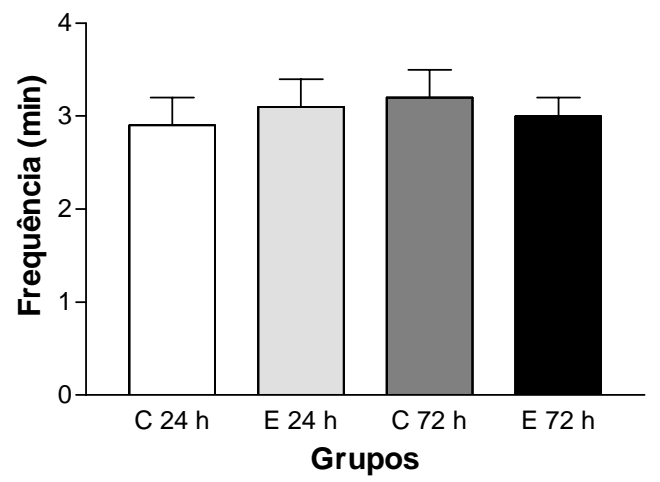

Intervalo Inter Intromissões

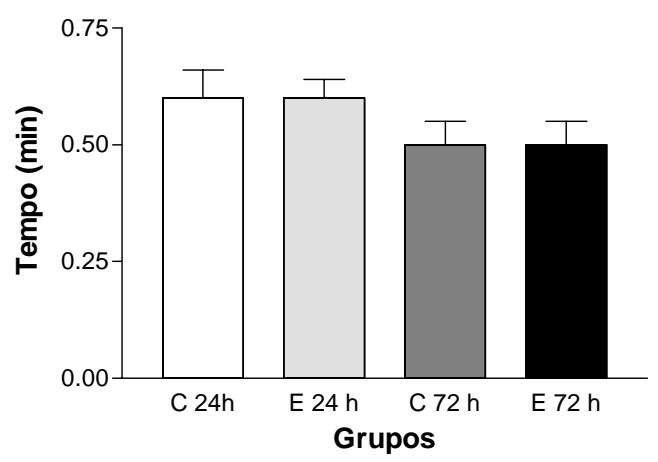

Eficiência Copulatória

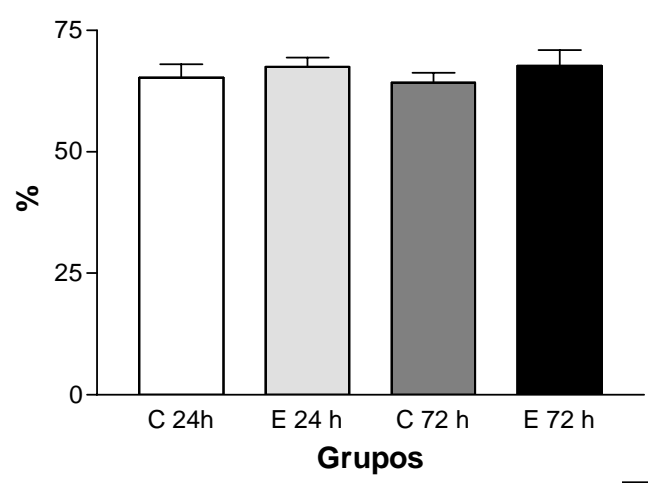

Intromissões

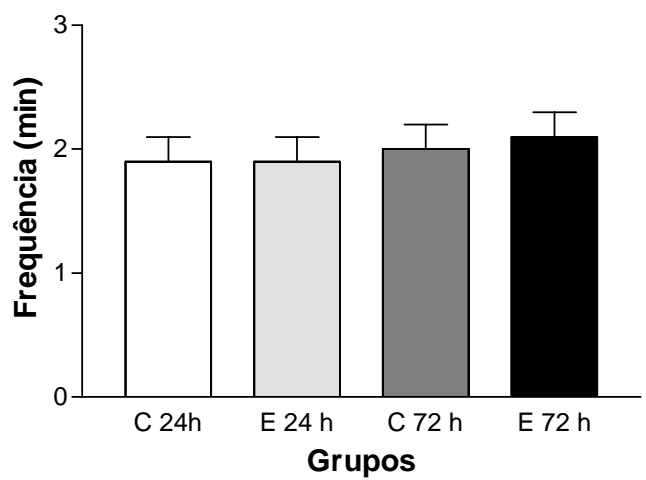

Atividade Sexual

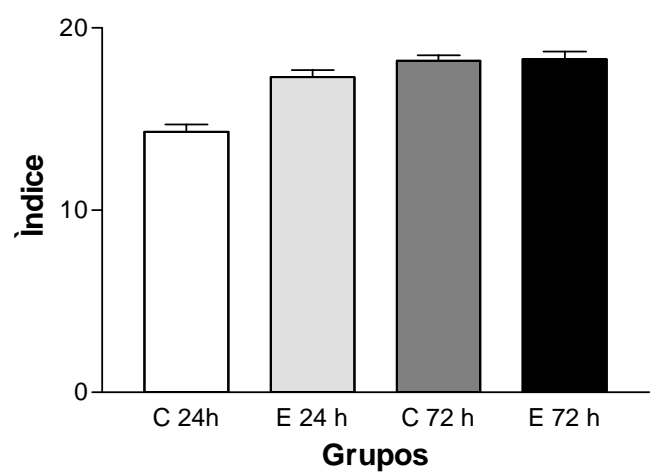

Frequência de Ejaculação

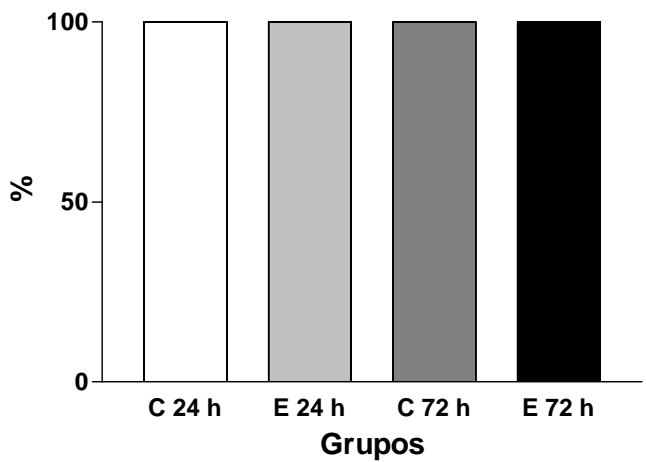

C $24 \mathrm{~h}$

E $24 \mathrm{~h}$

C $72 \mathrm{~h}$

E $72 \mathrm{~h}$

Figura 8. Efeito da moxidectina (0,2 mg/kg) em índices do comportamento sexual de ratos experientes. São apresentadas as médias e respectivos erros padrões. $\mathrm{P}>0,05$, ANOVA. 


\section{DISCUSSÃO}

Os modelos comportamentais podem mostrar efeitos de diferentes agentes químicos sobre o sistema nervoso central. No presente trabalho alguns modelos foram empregados para estudar os possíveis efeitos centrais da moxidectina e, em particular no comportamento sexual de ratos machos.

Neste trabalho, empregou-se a dose de $0,2 \mathrm{mg} / \mathrm{kg}$, usada clinicamente em diferentes espécies animais, e as doses de 2,0 e 20,0 mg/kg, visando uma maior penetração no sistema nervoso central. Acrescente-se, ainda, que se procurou empregar doses que obedecem à escala logarítmica, pois, sabe-se que a intensidade do efeito é, dentro de certos limites, diretamente proporcional à dose colocada nesta escala.

As observações comportamentais foram realizadas às 6, 24, 48 e 72 horas após a administração da moxidectina, uma vez que esta droga quando administrada por via subcutânea, tem pico plasmático entre 7-8 horas e 1/2 vida de 80 horas (FAO/WHO, 1995).

Dentre os vários modelos comportamentais usados para avaliar os efeitos de drogas no sistema nervoso central, um dos mais empregados é a atividade geral. Esta pode se medida no campo aberto, que é um aparelho de observação direta, muito utilizado em estudos de psicofarmacologia animal, por ser simples e proporcionar uma medida rápida e fácil dos diversos comportamentos que podem ser claramente definidos (BERNARDI e PALERMO-NETO, 1980). A atividade geral medida no 
campo aberto pode ser útil para definir doses, vias de administração e a latência para o aparecimento do efeito de uma substância química a ser estudada.

Assim, no Experimento 1 estudou-se os possíveis efeitos estimulantes/depressores, a latência e a duração destes após administração de 0,2; 2,0 e $20,0 \mathrm{mg} / \mathrm{kg}$ de moxidectina na atividade geral dos ratos observados no campo aberto. Neste experimento foram detectadas poucas alterações significantes, indicando que mesmo altas doses não alteram o comportamento de ratos no campo aberto. (Tab.2; Fig.1)

Sabe-se que os agonistas de receptores GABAérgicos reduzem a atividade locomotora e que este efeito é devido principalmente a estimulação de receptores $\mathrm{GABA}_{\mathrm{B}}$, uma vez que a administração intracerebro-ventricular de baclofen (agonista do receptor $\mathrm{GABA}_{\mathrm{B}}$ ) induziu imobilidade quase total de ratos, enquanto que os agonistas de receptores $\mathrm{GABA}_{\mathrm{A}}$, como o ácido animopropanesulfônico não afetou a atividade locomotora, e o THIP teve um efeito intermediário (AGMO e GIORDANO, 1985). No mesmo sentido, NISSBRANDT e ENGBERG (1996) observaram, em camundongos, que a administração intraperitoneal dos agonistas de receptores $\mathrm{GABA}_{\mathrm{B}}$ (baclofen e ácido $\gamma$-hidroxibutírico - GHBA) induziram ataxia, diminuição da atividade locomotora, diminuição do tono muscular e hipnose; a ação sobre a atividade locomotora foi revertida pelo pré-tratamento com o antagonista específico de receptor $\mathrm{GABA}_{\mathrm{B}}$ (ácido 3-aminopropil (dietoximetil) fosfínico CGP35348).

No presente trabalho, a ausência de efeitos da moxidectina na atividade locomotora de ratos, observados no campo aberto, sugere que esta droga não tem um perfil semelhante àquele dos agonistas de receptor $G_{A B A}$ acima descritos. Por outro lado, TEGNÉR et al. (1993), trabalhando com tronco cerebral-medula espinal 
da lampréia, que é um modelo experimental usado para o estudo do funcionamento da rede neuronal que controla o comportamento motor em vertebrados, mostraram que ambos os receptores $\mathrm{GABA}_{\mathrm{A}}$ e $\mathrm{GABA}_{\mathrm{B}}$ têm um papel modulador nesta rede neuronal espinhal, isto é, agem em conjunto na coordenação da locomoção.

No Experimento 2 avaliou-se a coordenação motora dos animais tratados com diferentes doses de moxidectina na trave elevada. Os resultados mostraram que a moxidectina é capaz de prejudicar a coordenação motora dos animais. Este efeito foi observado após a administração da menor dose da droga às 6, 48 e 72 horas, embora às 24 horas houvesse uma tendência em prejudicar a coordenação motora. As maiores doses empregadas mostraram este efeito a partir das 24 horas, sendo detectado até a última sessão de observação (72 horas). Este efeito pode ser atribuído, ao menos em parte, à ação da moxidectina em receptores GABAérgicos, modulando a coordenação motora. (Tab.3; Fig.2)

Em função dos achados na trave elevada, que mostraram, a partir das 24 horas, prejuízo na coordenação motora provocado pelas duas maiores doses de moxidectina, e considerando as características farmacocinéticas da droga, nos Experimentos 3 e 4 a observação do comportamento sexual foi feita às 24 ou 72 horas após a administração da droga.

No Experimento 3, dentre os vários parâmetros analisados, observou-se que apenas a dose de $0,2 \mathrm{mg} / \mathrm{kg}$ de moxidectina foi capaz de reduzir o total de montas incompletas e intromissões no tempo total de observação (40 minutos), às 24 horas Esta mesma dose causou também este efeito, às 72 horas, e ainda aumentou as latências para $1^{\mathrm{a}}$ monta e $1^{\mathrm{a}}$ intromissão, nos animais ingênuos (Tab.4; Fig.3, 4, 5). Já nos animais experientes (Experimento 4), nenhuma alteração significante foi 
observada nos diferentes parâmetros do comportamento sexual dos ratos que receberam a dose terapêutica de moxidectina (0,2 mg/kg). (Tab.5; Fig.6, 7, 8)

MEISEL e SACHS (1994) ressaltam que quando se observa o comportamento sexual do macho, são analisados dois aspectos distintos: a) a motivação ou apetite sexual ou, ainda, libido; e b) a performance ou também chamada de consumação ou potência sexual. Apesar desta distinção, ambos estão intimamente relacionados.

A motivação sexual é avaliada principalmente pela latência para $1^{\mathrm{a}}$ monta e latência para a $1^{\mathrm{a}}$ intromissão e ambas podem ser alteradas por fatores sensoriais e motores (BITRAN e HULL, 1987; MEISEL e SACHS, 1994; AGMO, 1997). AGMO (1997) relata que tanto o intervalo pós-ejaculatório (ou período refratário), como o número de montas podem também refletir a motivação sexual, embora estes apresentem limitações e desvantagens em função das diferentes manipulações experimentais.

Os resultados obtidos no Experimento 3, no qual observou-se aumento das latências para $1^{\mathrm{a}}$ monta e $1^{\mathrm{a}}$ intromissão, indicam redução da motivação sexual dos ratos ingênuos que receberam moxidectina e observados após 72 horas. Deve ser salientado, que embora a moxidectina promova incoordenação motora, os ratos que foram observados 24 horas após receberem a droga nas doses de 2,0 e 20,0 mg/kg não tiveram alteração nos vários parâmetros do comportamento sexual, indicando, portanto, que a redução da motivação sexual não é conseqüência do prejuízo motor.

MEISEL e SACHS (1994) mencionam vários trabalhos que demonstram alterações em parâmetros do comportamento sexual de ratos machos ingênuos, que não são mais observadas em ratos experientes. No mesmo sentido, CRUZCASALLAS et al. (2000) mostraram que a experiência sexual induz uma melhora 
quantitativa da performance sexual e que os parâmetros de motivação sexual (latência para $1^{\mathrm{a}}$ monta e latência para a $1^{\mathrm{a}}$ intromissão) são mais sensíveis a mudanças induzidas pela experiência sexual. No presente trabalho, a ausência de efeitos no comportamento sexual de ratos experientes tratados com moxidectina, pode ser atribuída à experiência sexual dos animais, que impediu a redução da sua motivação sexual. (Tab.5; Fig.6, 7, 8)

A performance sexual pode ser avaliada pelo número de intromissões, latência para a $1^{\mathrm{a}}$ ejaculação, intervalo pós-ejaculatório, número de ejaculações em um dado intervalo de tempo, eficiência copulatória e índice copulatório (BITRAN e HULL, 1987; MEISEL e SACHS, 1994; AGMO, 1997). Há ainda parâmetros que indicam tanto a motivação como a performance sexuais: a freqüência de montas por minuto, o intervalo inter-intromissões, o índice de atividade sexual e o total de montas.

AGMO e PAREDES (1985), como citado anteriormente, observaram que a

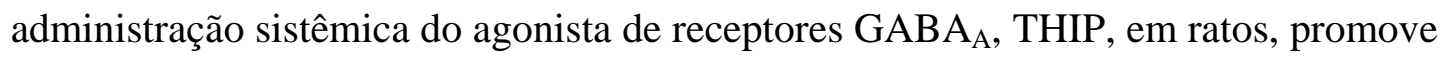
a diminuição no número de montas e intromissões, enquanto que o agonista de receptor $\mathrm{GABA}_{B}$ inibe o comportamento copulatório. Já MEISEL e SACHS (1994) observaram que a infusão de GABA na área pré-óptica medial promoveu um aumento na latência para intromissão. Neste sentido, a redução no número de montas e intromissões e o aumento na latência para intromissão, provocadas pela moxidectina, e a ausência de efeitos inibitórios sobre o comportamento copulatório, sugerem que esta droga tenha um perfil semelhante a de um agonista de receptores $\mathrm{GABA}_{\mathrm{A}}$. E, ainda, considerando que agonistas de receptores $\mathrm{GABA}_{\mathrm{B}}$ reduzem a locomoção, efeito este não observado no presente estudo, corroboram com a ação desta droga apenas em receptores $\mathrm{GABA}_{\mathrm{A}}$. Acrescente-se, ainda que o receptor 
$\mathrm{GABA}_{\mathrm{A}}$ está acoplado diretamente aos canais de cloro (RANG e DALE, 1993), que são também o local de ação da moxidectina (DUCE e SCOT, 1985; DAWSON et al, 2000).

Sabe-se que os sítios de receptores $\mathrm{GABA}_{\mathrm{A}}$ estão presentes na área pré-óptica medial (BITRAN e HULL, 1987) e esta é a principal responsável pela regulação neural do comportamento sexual de machos (MEISEL e SACHS, 1994, VAN FURTH et al., 1995). Provavelmente os efeitos da moxidectina aqui observados são conseqüência de sua atuação nesta área. 


\section{CONCLUSÃO}

A moxidectina prejudicou o comportamento sexual de ratos machos ingênuos e a coordenação motora, porém não alterou a atividade geral observada no campo aberto. Estes efeitos foram atribuídos a uma ação central da moxidectina em receptores $\mathrm{GABA}_{\mathrm{A}}$. 


\section{REFERÊNCIAS}

AGMO, A. Male rat sexual behavior (Protocol). Brain Research Protocols, v. 1, p. 203-209, 1997

AGMO, A.; GIORDANO, M. The locomotor-reducing effects of GABAergic drugs do not depend on the $\mathrm{GABA}_{\mathrm{A}}$ receptor. Psychopharmacology, v. 87, p. 51-54, 1985.

AGMO, A.; PAREDES, R. GABAergic drugs and sexual behaviour in the male rat. European journal of Pharmacology, v. 112, p. 371-378, 1985

AGMO, A; PAREDES, R.; FERNÁNDEZ, H. Differential effects of GABA transaminase inhibitors on sexual behavior, locomotor activity, and motor execution in male rat. Pharmacology Biochemistry and Behavior, v. 28, p. 3345-347, 1987.

AHLENIUS, S.; LARSSON, K. Apomorphine and haloperidol-induced effects on male rat sexual behavior. No evidence for actions due to stimulation of central dopamine autoreceptors. Pharmacology Biochemistry and Behavior, v. 21, p. 463466, 1984.

ALVINERIE, M; SUTRA, J.F.; CABEZAS, I.; RUBILAR, L.; PEREZ, R. Enhanced plasma availability of moxidectin in fasted horses. Journal of Equine Veterinary Science, v. 20, n. 9, p. 575-578, 2000.

ARENA, J.P. Expression of Caenorhabditis elegans mRNA in Xenopus oocytes: a model system to study the mechanismof action of avermectins. Parasitology Today, v. 10, p. 35-37, 1994.

ARENA, J.P.; LIU, K.K.; PARESS, P.S.; CULLY, D.F. Avermectin-sensitive chloride currents induced by Caenorhabditis elegans RNA in Xenopus oocytes. Molecular Pharmacology, v. 40, p. 368-374, 1991.

ARENA, J.P.; LIU, K.K.; PARESS, P.S.; SCHAEFFER, J.M.; CULLY, D.F. Expression of glutamate-activated chloride current in Xenopus oocytes injected with Caenorhabditis elegans RNA: evidence for modulation by avermectin. Molecular Brain Research, v. 15, p. 339-348, 1992

AYRES, M.C.C. ; ALMEIDA, M.A.O. Agentes Antinematódeos. In: SPINOSA, H.S.; GÓRNIAK, S.L.; BERNARDI, M.M. Farmacologia aplicada à medicina veterinária. Rio de Janeiro : Guanabara Koogan, 2002. p. 483-486. 
BERNARDI, M.M.; PALERMO-NETO, J. Atividade geral: conceito e medidas. Psicologia, São Paulo, n. 1, p. 43-51, 1980.

BITRAN, D.; HULL, E.M. Pharmacological Analysis of Male Sexual Behavior. Neuroscience and Biobehavioral Reviews, v. 11, p. 365-389, 1987

BITRAN, D.; MILLER, S.A.; McQUADE, D.B.; LEIPHEIMER, R.E., SACHS, B.D. Inhibition of sexual reflexes by lumbosacral injection of GABAB agonist in male rats. Pharmacology, Biochemistry and Behavior, v. 31, p. 657-666, 1989.

BROADHURST, P.L. Experiments in psychogenetics. In:EYSENK, H.J. Experiments in personality. Lodon : Routledge and Kegan Paul, 1960. p.31-61.

BURG, R.W.; MILLER, B.M.; BAKER, E.F.; BIRNBAUM, J.; CURRIE, S.A.; HARTMAN, R.; KONG, Y.L., MONAGHAN, R.L.; OLSON, G.; PUTTER, I.; TUNAC, J.B.; WALLICK, H.; STAPLEY, E.O.; OIWA, R.; OMURA, S. Avermectins, new family of potent anthelmintic agents: producing organism and fermentation. Antimicrobial Agents Chemotherapy, v. 15, p. 361-367, 1979.

CAMPBELL, W.C. (ed) Ivermectin and Abamectin. New York : Springer-Verlag, 1989.

CARCELES, C.M.; DIAZ, M.S.; VICENTE, M.S.; SUTRA, J.F.; ALVINERIE, M.; ESCUDERO, E. Milk kinectics of moxidectin and doramectin in goats. Research in Veterinary Science, v. 70, n. 3, p. 227-231, Jun. 2001.

CLELAND, T.A. Inhibitory glutamate receptor channels. Molecular Neurobiology, v. 13, p. 97-136, 1996.

CONDER, G.A.; THOMPSON, D.P. ; JOHNSON, S.S. Demonstration of coresistance of Haemonchus contortus to ivermectin and moxidectin. Veterinary Record, v. 132, p. 651-652, 1993.

CRAVEN, J.; BJORN, H.; HENNESSY, D; FRIIS, C; NANSEN, P. Pharmacokinectics of moxidectin and ivermectin following intravenous injection in pigs with different body compositions. Journal of Veterinary Pharmacology and Therapeutics, v. 24, n. 2, p. 99-104, 2001.

CULLY, D.F.; WILKINSON, H.; VASSILATIS, D.K.; ETTER, A.; ARENA, J.P. Molecular biology and eletrophysiology of glutamate-gated chloride channels of invertebrates. Parasitology, v.113(Suplemento), p. 191-200, 1996.

DUCE, I.R; SCOTT, R.H. Actions of hydro avermectin B 1 a om insect muscle. Br Journal of Pharmacology, v. 85, p. 395-401, 1985.

DUPUY, J.; ESCUDERO, E.; EECKHOUTTE, C.; SUTRA, J.F.; GALTIER, P.; ALVINERIE, M. In vitro metabolism of 14C-moxidectin by hepatic microsomes from various species. Veterinary Research Communications, v. 25, n. 5, p. 345354, Jul. 2001. 
EMAM, E.E.; EL-ABDALLA, O. Effects of ivermectin and moxidectin on fertility and some biochemical parameters in male rabbits. Egyptian Journal of Agricultural Research, v. 78, n. 1, Special Issue, p. 293-301, 2000.

FERNANDEZ-GUASTI, A.; LARSSON, K.; BEYER, C. Comparison of effects of different isomers of bicuculline infused in the preoptic area on male sexual behavior. Experientia, v. 41, p. 1414-1416, 1985

FERNANDEZ-GUASTI, A.; LARSSON, K.; BEYER, C. Effect of bicuculline on sexual activity in castrated male rats. Physiology and Behavior, v. 36, p. 235-237, $1986 \mathrm{a}$

FERNANDEZ-GUASTI, A.; LARSSON, K.; BEYER, C. GABAergic control of masculine sexual behavior. Pharmacology, Biochemistry and Behavior, v. 24, p. 1065-1070, 1986b

FERNANDEZ-GUASTI, A.; LARSSON, K.; VEGA-SANABRIA, J. Depression of postejaculatory ultrasonic vocalization by $(+)$ bicuculline. Behavior Brain Research, v. 19, p. 35-39, 1986c

FISHER, M.H.; MROZIK, H. Chemistry. In: CAMPBELL, W.C. (ed.) Ivermectin and Abamectin. New York: SPRINGER-VERLAG, 1989. p. 1-23.

FORRESTER, S.G.; PRICHARD, R.K; BEECH, R.N. A glutamate-gated chloride channel subunit from Haemonchus contortus: Expression in a mammalian cell line, ligand binding, and modulation of anthelmintic binding by glutamate. Biochemical Pharmacology, v. 63, p. 1061-1068, 2002.

GOKBULUT, C.; NOLAN, A.M.; McKELLAR, Q.A. Plasma pharmacokinetics and faecal excretion of ivermectin, doramectin and moxidectin following oral administration in horses. Eqüine Veterinary Journal, v. 33, n. 5, p. 494-498, 2001.

GRAF PAD INSTAT tm Copyright (C) GraphPad software. V2.01

JEFFERY, N.D. ; BLAKEMORE, W.F. Locomotor deficits induced by experimental spinal cord demyelination are abolished by spontaneous remyelination. Brain Research, v. 120, p. 27-37, 1997.

JOINT FAO / WHO Expert Committee on Food Additives, 45, Genebra, SW, 1995. Evaluation of certain veterinary drug residues in food. Genebra, 1995. P. 15-21. WHO techinical report series, 864.

KANDELL, E.C.; SCHWARTZ, J.H.; JESSEL, T.M. Fundamentos da Neurociência e do Comportamento. Rio de Janeiro : Prentice-Hall do Brasil ltda., 1997

KOHLER, P. The biochemical basis of anthelmintic action and resistance. International Journal for Parasitology, v. 31, n. 4, p. 336-345, Apr. 2001. 
LEIPHEIMER,R.E.; SACHS, B.D. GABAergic Regulation of Penile Reflexes and Copulation in Rats. Physiology \& Behavior, v. 42, p. 351-357, 1988.

MANUAL DE PRODUTOS VETERINÁRIOS, São Paulo: Sindicato Nacional da Indústria de Produtos Veterinários (SIDAN), 2001-2002. p. 177, 285, 359, 463-464.

MAS, M. Neurobiological Correlates of Masculine Sexual Behavior. Neuroscience and Biobehavioral Reviews, v. 19, n. 2, p. 261-277, 1995.

MISHIMA, H.; IDE, J.; MURAMATSU, S.; ONO, M. Milbemycins, a new family of macrolide antibiotics, structure determination of milbemycins D, E, F, G, H, J and K. Journal Antibiótica, v. 36, p. 980-990, 1983.

MOLENTO, M.B.; PRICHARD, R.K..Effect of multidrug resistance modulators on the activity of ivermectin and moxidectin against selected strains of Haemonchus contortus infective larvae. Pesquisa Veterinária Brasileira, v. 21, n. 3, p. 117-121, 2001.

MOLENTO, M.B.; WANG, G.T.; PRICHARD, R.K. Decrease ivermectin and moxidectin sensitivity in Haemonchus contortus selected with moxidectin over 14 generations. Veterinary Parasitology, v.86, p. 77-81, 1999.

PAUL, A.J.; TRANQUILLI, W.J.; HUTCHENS, D.E. Safety of moxidectin in avermectin-sensitive collies. American Journal of Veterinary Research, v. 61, n.5, p. 482-483, May, 2000.

PEREZ, R.; CABEZAS, I.; SUTRA, J.F.; GALTIER, P., ALVINERIE, M. Faecal excretion profile of moxidectin and ivermectin after oral administration in horses. Veterinary Journal, v.161, n. 1, p. 85-92, Jan. 2001.

QURESHI, G.A.; AND SÖDERSTEN, P. Sexual activity alters the concentration of amino acids in the cerebrospinal fluid of male rats. Neuroscience Letters, v. 70, p. 374-378, 1986.

RAMIREZ, O.A.; CARRER, H.F.; NASELLO, A.G. Prenatal amphetamine exposure: ovulation, sexual behavior and hypotalamic monoamine content in rats. Pharmacology Biochemistry and Behavior, v. 11, n. 6, p. 605-609, 1979.

RANG, H.P.; DALE, M.M. Farmacologia. 2 ed. Rio de Janeiro : Guanabara Koogan, 1993. p.351-369. Transmissão química e ação das drogas no sistema nervoso central.

RODER, J.D. An overview of ivermectin toxicosis. Veterinary and Human Toxicology, v. 40, n. 6, p.369-370, 1998.

SACHS, B.D.; GARINELLO, L.D. Interaction between penile reflexes and copulation in male rats. Journal of Comparative and Physiological Psychology, v. 92, n. 4, p. 759-767, 1978. 
SCHAEFFER, J.M.; HAINES, H.W. Avermectin binding in Caenorhabditis elegans: a two-state model for the avermectin binding site. Biochemical Pharmacology, v.38, p. 2329-2338, 1989.

SHOOP, W.L. Ivermectin Resistance. Parasitology Today, v. 9, n. 5, p. 154-159, 1993

SHOOP, W.L.; MROZIK, H.; FISHER, M.H . Structure and activity of avermectins and milbemycins in animal health, Veterinary Parasitology, v. 59, p. 139-159, 1995.

SHOOP, W.L; HAINES, H.W.; MICHAEL, B.F.; EARY, C.H. Mutual resistance to avermectins and milbemycins: oral activity of ivermectin and moxidectin against ivermectin-resistant and susceptible nematodes. The Veterinary Record, v. 30, p.445-447, Oct. 1993.

SÖDERSTEN, P. Effects of anti-oestrogen treatment of neonatal male rats on lordosis behaviour and mounting behaviour in the adult. Journal of Endocrinology, v. 76, p. 241-249, 1978.

SÖDERSTEN, P.; ENEROTH, P. Neonatal treatment with antioestrogen increases the diurnal rhythmicity in the sexual behaviour of adult male rats. Journal of Endocrinology, v. 85, p. 331-339, 1980.

SÖDERSTEN, P.; ENEROTH, P.; HANSSON, T.; MODE, A.; JOHANSSON, D.; NÄSLUNG, B.; LIANG, T.; GUSTAFSSON, J.A. Activation of sexual behavior in castrated rats: the role of estradiol. Journal of Endocrinology, v. 111, p. 455-462, 1986.

STEEL, J.W. Pharmacokinectics and metabolism of avermectins in livestock. Veterinary Parasitology, v. 48, p. 45-57, 1993.

TAKIGUCHI, Y.; MISHIMA, H.; OKUDA, M.; TERAO, M. Milbemycins, a new family of macrolide antibiotics: fermentation, isolation and physico-chemical properties. Journal of Antibiotcs, v. 33, p. 1120-1127, 1980.

TRACY, J.W.; WEBSTER JR., L.T. Fármacos usados no tratamento das helmintíases. In: HARDMAN, J.G.; LIMBIRD, L.E.; MOLINOFF, P.B.; RUDDON, R.W.; GOODMAN GILMAN, A. Goodman \& Gilman, As bases farmacológicas da terapêutica. Rio de Janeiro: McGraw-Hill, 1996. p. 746-748.

TURNER, M.J.; SCHAEFFER, J.M. Mode of the action of ivermectin. In: CAMPBELL, W.C. (ed.) Ivermectin and Abamectin. New York: SPRINGERVERLAG, 1989. p.73-88.

WOLSTENHOLME, A.J. Glutamate-gated chloride channels in Caenorhabditis elegans and parasitic nematodes. Biochemial Society Transactions, v. 25, p. 830834, 1997. 
